This is a post-peer-review, pre-copyedit version of an article published in Synthese. To cite, please refer to the final published version:

\title{
The Public Relevance of Philosophy
}

\author{
Stijn Conix ${ }^{1}$, Olivier Lemeire ${ }^{2} \&$ Pei-Shan $\mathrm{Chi}^{3}$
}

${ }^{1}$ stijn.conix@kuleuven.be

Centre for Logic and Philosophy of Science, Institute of Philosophy, KU Leuven, Vesaliusstraat 2, 3000 Leuven, Belgium

ºlivier.lemeire@kuleuven.be

Centre for Logic and Philosophy of Science, Institute of Philosophy, KU Leuven, Vesaliusstraat 2, 3000 Leuven, Belgium

33peishan.chi@kuleuven.be

ECOOM, KU Leuven, Naamsestraat 61, 3000 Leuven, Belgium

\begin{abstract}
Various authors have recently expressed doubts about the public relevance of philosophy. These doubts target both academic philosophy in general and particular subfields of philosophy. This paper investigates whether these doubts are justified through two tests in which the lack of public relevance of a philosophical paper is operationalized as the degree to which that paper is isolated. Both tests suggest that academic philosophy in general is more isolated from the broader public than it should be, and confirm the hypothesis that some subfields of philosophy are more isolated than others. We argue that this lack of public relevance is caused by the incentive structure of academic philosophy and discuss a range of individual-level and incentive-level solutions.
\end{abstract}

Keywords: Public philosophy; public relevance; societal impact; altmetrics; isolation;

\section{Introduction}

In Philosophy Inside Out, Philip Kitcher (2011, p. 248) asks his readers to imagine a world in which professional pianists have moved from performing traditional repertoire to only technically difficult etudes. In such a world where Beethoven's last sonata would have to make place for 'Quadruple Tremolo 41,' professional musicians only play for other professionals and not for a broad audience that prefers esthetically pleasing works.

The point of Kitcher's imaginary scenario is to critique philosophy; at least some of the work currently generated by professional philosophers is highly technical and of little significance to the broader 
public that could benefit from philosophical thinking. Many other philosophers have made similar points. Comparing contemporary philosophy to thinking about obscure variants of chess - called Chmess - Dennett (2006, p. 36) writes that 'many projects in contemporary philosophy are artifactual puzzles of no abiding significance.'

Of course, not all philosophical research is just a matter of solving artifactual puzzles. The authors mentioned above, however, worry that too much of current academic philosophy is simply irrelevant to people who are not professional philosophers. In this paper, we address this worry and present empirical evidence that leads us to conclude that current academic philosophy is indeed less publicly relevant than it should be. Starting from this conclusion, we discuss various individual-level and incentive-level solutions that have been raised in the literature to increase the level of publicly relevant academic philosophy.

To be clear from the start, however, we readily recognize that even philosophical research that is only relevant to other professional philosophers can be interesting, valuable, and of high quality. However, philosophical research is typically state funded and state funds are scarce. There are innumerable other valuable ends, both in academic research and more generally, that could be financially supported. Hence some criteria are needed to select from all the interesting (philosophical) research topics, those that should be pursued with public funding. We believe it is evident that all philosophical research that is publicly funded, should also be relevant - in some way, at some time - to the public that is funding it. Even for the blue-sky fundamental research that will always be needed in any discipline, the justification for using public funds on such research must lie in the possible relevance down the line, and we should not be too quick in assuming that this will be the case. Especially in philosophy, it is hard to find many examples of research results that were not yet publicly relevant at the time but became highly relevant at a later stage.

In talking about public relevance, we explicitly want to resist two opposing tendencies. On the one hand, some believe the only possible value of academic research lies in its practical applications or in the economic return on investment. Especially in a North American context, academics will be keenly aware of political proposals that rely on this narrow instrumentalist view to defund research in the humanities. Surely, however, philosophical research can be relevant to the public in ways that are not of such immediate practical nature. For example, we believe a paper like this one, which discusses the optimal use of state funds and suggests ways of improving the current distribution, is publicly relevant as well.

On the other hand, however, some believe all philosophical research is intrinsically valuable and that no further questions should be asked about the use of public funds to support this research. Sassower (2018, p. 66), for example, writes that:

"Given the neoliberal pressures of the economy and the political climate that accompanies these pressures, the academy could be seen, just like monasteries of yesteryear, as a refuge. [...] The luxury of pursuing one's heart's desire, remaining curious and imaginative, and following a seemingly esoteric research program for the love of it should be publicly supported and maintained within the academy." 
We disagree. Philosophical research might indeed be intrinsically valuable to a philosopher, just like plane spotting might be intrinsically valuable to a plane spotter. Yet no one believes public funds should be used to support someone's plane spotting hobby. Philosophical research is different from plane spotting because it can be publicly relevant and deserving of public funding. The question is, however, to what extent this is the case for current academic research in philosophy.

In the next section, we start this paper off by defining publicly relevant research projects as those projects that would receive funding given an ideal democratic deliberation, in the sense of Kitcher (2001). We then use the notion of isolation to operationalize this ideal. Building on this operationalization, we empirically test (1) the public relevance of philosophy in general and (2) the difference in public relevance between three subfields of philosophy. We do this because some of the authors that criticize philosophy's lack of public relevance also claim that some areas of philosophy are less publicly relevant than other areas. More precisely, Kitcher (2011) claims that two kinds of philosophy are often more publicly relevant: philosophy that engages with other fields of science call it Philosophy of Science (PoS) - and philosophy involved with identifying and understanding what we value - call it Value Theory (VT). Kitcher argues that these subfields produce publicly relevant work more often than the subfield that could be called LEMM - philosophy of language, epistemology, philosophy of mind and metaphysics. Section 3 presents two empirical tests - one using altmetric data of philosophical journal papers, and one using the abstracts of philosophical journal papers - to test the hypothesis that a significant portion of current academic philosophy is isolated from the broader public and that this is especially the case for LEMM.

Based on the results of these tests, section 4 argues that the current incentive structure in academic philosophy plays an important role in fostering research that is isolated from the broader public. In sections 5 and 6 , we discuss several individual and incentive-level changes that could increase the level of publicly relevant work in philosophy. Throughout the paper, and in particular in those final two sections, we draw extensively on the recent and burgeoning literature on what socially engaged philosophy is (Cartieri \& Potochnik 2014; Fehr \& Plaisance 2010; Plaisance \& Elliott 2020), how professional philosophers feel about it (Plaisance et al. 2019; Tiberius 2017), and how it could be implemented and promoted (Burroughs 2020; Frodeman \& Briggle 2016; Plaisance et al. 2021).

\section{Funding, isolation, public relevance}

Philosophical research is expensive and typically state funded. To give a sense of just how expensive it is, consider that at our home institution, publicly funded philosophical research cost $€ 34.2$ million between 2015 and 2020 , totaling up to nearly $€ 240,000$ per full-time tenured researcher per year. As a large part of this funding was spent on hiring junior staff, we could also include the opportunity cost of these researchers' time and the fact that society has invested a lot already in the subsidized education of these professional philosophers. ${ }^{1}$ If we extrapolate these numbers to other institutions and countries, we can safely assume that an enormous amount of public money is spent on philosophical research.

\footnotetext{
${ }^{1}$ This includes only $30 \%$ of the philosophers' salaries, as they typically also have other duties. See supplementary materials (Online resources, A) for a full breakdown of the costs into various components.
} 
Given the scarcity of this public money, it would be unjust if it were put to use by any one philosopher simply to support 'the luxury of pursuing one's heart's desire' if the resulting research is only relevant to that philosopher or to a handful of like-minded professionals. Instead, resources of public origin should be used to support research that is also relevant in some way to the public. In fact, there is an even closer connection between the notions of public relevance and public funding. A good measure of which research projects are relevant to the public is whether they would receive public funding through a hypothetical ideal democratic deliberation, as envisioned by Kitcher (2001). In such an ideal democratic deliberation, well-informed deliberators that represent the interests of different segments of society decide which research topics we should pursue. Importantly, these deliberators take into account not just their own interests but also those of others now and in the future. If such ideal deliberation, in which all of society is appropriately represented, were to allocate funding to a research proposal, it would seem that that research is by definition publicly relevant.

Kitcher's ideal, which he introduces as a measure to evaluate science's actual research agenda, has been challenged on various grounds. Most relevant to the purposes of this paper is that it provides insufficient guidance in actually setting academia's research agenda. That is, it is very difficult to predict what the outcome - in terms of selected research projects - of Kitcher's idealized procedure would be (Philippi 2019). This is due to the complexity of taking into account the preferences of all current and future groups of people represented in the deliberation, the innumerable possible research projects, the different amounts of funding these projects can get, and the incomparability of research problems from different fields. Indeed, given the multiplicity of relevant epistemic and nonepistemic values and the trade-offs between them, this outcome is probably vastly underdetermined by Kitcher's ideal.

While we acknowledge that Kitcher's ideal does not determine which research projects to fund, we believe that it does have negative heuristic value. Even if it is hard to tell which research projects should be funded, it may sometimes be possible to estimate with some certainty which research projects would definitely not be funded. Consider Dennett's (2006) example of research questions about various possible variations on chess: What, for example, is the quickest possible mate in nocastling chess if white can only move the queen after black has moved its dark-squared bishop twice? ${ }^{2}$ If research funding were to be allocated based on an idealized democratic procedure, it is quite certain no money would be set aside to answer 'Chmess-questions' like this. Using Kitcher's ideal, then, it is possible to say of at least some research projects that they would probably not make the cut.

Even though Chmess-questions are perhaps only uncontroversial as examples of research topics that should not get funding because they are not actually competing, it can still be fruitful to consider why such questions would not make the cut. We believe that funding would not be allocated to such research topics because they are too isolated: they have very little or no impact beyond the research topic itself, and thus cannot benefit society or a substantial proportion of its members now or in the foreseeable future. Because an idealized democratic deliberation process would presumably only

\footnotetext{
${ }^{2}$ Rather unfortunately for Dennett's example, Google's DeepMind and former world champion Vladimir Kramnik recently investigated various chess variants to find a way of decreasing the importance of opening preparation in chess (Tomašev et al. 2020). Note however, in defense of Dennett, that this was research on the problem of opening preparation and not research on these chess variants for the sake of figuring out these puzzles.
} 
select research projects that at least some part of society would find interesting or could benefit from, isolated projects would not be selected.

Hence one way of operationalizing the negative heuristic value of Kitcher's idealized deliberation is to consider the extent to which research projects are isolated. In the case of philosophical research, this means that research topics are isolated when they are unlikely to affect anyone outside of one's own philosophical research community, and would therefore be unlikely to be awarded funding if the decision was based on an idealized democratic process. Because of the underdetermination problem, this operationalization is purely negative: 'isolation' serves to identify philosophical research that would probably not be funded but is no direct indication of the type of research that should be funded.

'Isolation' is of course a vague term, as philosophical research can be isolated from various audiences. Most importantly, it can be isolated from other philosophers and academics, or isolated from members of the non-academic public such as lay people, policy makers, and various organizations. This corresponds to the reverse fact that research can be publicly relevant directly - by virtue of its impact on a non-academic audience - or indirectly - by virtue of its impact on other academics, resulting in downstream relevance for a non-academic audience. Other studies have already looked at the extent to which various philosophical research topics and philosophical subfields are isolated from other philosophical research and from academia more generally (e.g., Higgins \& Smith 2013; McLevey et al. 2018). Most relevantly, Chi \& Conix (2021) show that research in philosophy of language, epistemology, philosophy of mind and metaphysics (LEMM) is more isolated from other academic fields than research in philosophy of science (PoS) and value theory (VT). For example, for the research topics tested in that paper, less than $8 \%$ of the citations of LEMM papers came from outside of philosophy, while for VT this was $40 \%$ and for PoS even more than $60 \%$. Similar results were found for the average number of citations from outside philosophy and for the reference lists of those papers. We will assume that these results hold and will focus here solely on direct public relevance. That is to say, we will only measure the extent to which philosophical research is isolated from a broader non-academic public. ${ }^{3}$ We turn to these measurements in the next section.

\section{Measuring the isolation of academic philosophy}

A major advantage of cashing out lack of public relevance as isolation, is that isolation is easier to operationalize: we simply have to look at the connections between philosophical research and society at large. In this sense, research that results in popular books is publicly relevant, as is research that deals with questions that the public values. This section investigates the isolation of academic philosophy through two tests. These tests aim to investigate the hypotheses (1) that highly isolated work is common in philosophy and (2) that LEMM tends to be more isolated than PoS and VT.

Before we discuss these tests, we need to be more precise about the notion of isolation. There are two types of connections between philosophical research and a broad, non-academic audience that are relevant here. First, the topic of the research can be of interest to people outside of academia. In this sense, research is isolated if it focuses on a topic that is only of interest to one's own research

\footnotetext{
${ }^{3}$ This means that in the rest of this paper our negative conclusions about the public relevance of academic philosophy are conditional upon this caveat that we are only discussing the extent to which philosophy is isolated from a broader non-academic audience.
} 
community. This dimension of isolation is what Fehr and Plaisance (2010) address with their framework of 'Socially Relevant Philosophy of Science'. Papers primarily devoted to meta-discourse, such as work on the state of the field or the compatibility of two positions, are prime examples of work that is not relevant in this sense. We will use the term 'content isolation' to refer to this type of isolation from society. Second, research can be connected to a broad audience by virtue of actually reaching that audience, for example when philosophical books are read by laypeople. Conversely, research may be isolated because it does not reach people beyond the research community it stems from, for example because they cannot access the papers or because these papers are written in a way that makes them hard to read for laypeople. This dimension of isolation is the focus of Cartieri and Potochnik's (2014, p. 910) framework of 'Socially Engaged Philosophy of Science', which recommends that "work is published in ways that reach relevant communities and is presented in terms that they will engage with." We will refer to this dimension of isolation as 'uptake isolation.'

To make sure we capture both content isolation and uptake isolation, we used two different methods for testing our hypotheses: we rated journal abstracts for the content isolation of the presented research, and we analyzed altmetrics (e.g., social media mentions, news outlet mentions) to evaluate the uptake isolation of philosophical papers. We present each of these tests in turn.

\subsection{Test 1: Content isolation based on journal paper abstracts}

Journal papers are arguably the main output of philosophical research. If philosophical research typically focuses on topics or questions that are relevant to a broad, non-academic audience, this would be expected to show in the content of the papers that result from that research. We therefore evaluated the abstracts of papers in LEMM, POS and VT to evaluate and compare their content isolation.

\section{Methods}

We selected the most cited articles from five top journals in LEMM, five top journals in VT, and five top journals in PoS for each year between 2009 and 2019. We chose top-cited papers because these are likely to reflect the kind of work that philosophers value. Journals were chosen based on Leiter polls for LEMM and VT, and based on impact factor for PoS. ${ }^{4}$ This amounted to 328 papers, the abstracts of which were scored independently as 'content-isolated' or 'not content-isolated.' The abstract of a paper was scored as 'not content-isolated' if at least one of the two following conditions was met:

- The authors aim to answer a question, resolve a problem or address an issue that is recognized as such by some people outside of academia.

- If the claims of the authors would be accepted as true by people outside of academia, this would most likely have an effect on the behavior of these people.

The first criterion aims to capture whether the research in question deals with something that people outside of academia care about. For example, a general paper on whether people have free will might score as relevant here, while a paper on the counter-examples to one particular argument against one particular view on free will might not. The second criterion aims to capture whether the research in

\footnotetext{
${ }^{4}$ See Supplementary materials, section B, for more details on the selection of journals and papers.
} 
question could lead to changes that are relevant to the lay public. For example, a paper that suggests policy changes to solve a concrete problem would be rated as relevant based on this criterion. Abstracts were scored as content-isolated if neither of these conditions was met. ${ }^{5}$

Because the rating criteria for relevance are inevitably vague and leave room for interpretation, all abstracts were rated by two of the authors of this paper as well as five other philosophers with different specializations. This way, we avoid that the results reflect the biases of one particular philosophical discipline or one particular interpretation of the rating criteria. To avoid that abstracts would be rated as 'content-isolated' simply because they are hard to understand or use specialized terminology, all raters were professional philosophers (PhD-student or Postdoc) used to reading academic journal papers. While the use of philosophical raters may lead to a bias in favour of philosophy's relevance, we preferred this over the bias against philosophy's relevance that would be inevitable if lay people not used to reading philosophy and its jargon would rate the abstracts.

\section{Results}

There was fair agreement between the seven raters (Fleiss kappa $=0.36, p<0.001$ ). Summing the seven ratings, we derived a score between 0 and 7 for each of the abstracts as a measure for isolation (and, inversely, relevance). There was a significant difference between PoS and VT, and between LEMM and VT, but not between PoS and LEMM. ${ }^{6}$ These differences are also clearly illustrated by the proportion of abstracts in each of the three categories that raters found unanimously content-isolated or not content-isolated: while about $60 \%$ of all abstracts in PoS and LEMM were rated as isolated by all raters, only $9 \%$ percent of all VT abstracts were unanimously considered isolated (see table 1 ).

Table 1:Differences between LEMM, POS and VT with respect to content isolation as rated by 7 raters.

\begin{tabular}{lccc} 
& $\begin{array}{c}\text { mean number of raters to rate } \\
\text { an abstract 'not isolated' }\end{array}$ & $\begin{array}{c}\text { \% of abstracts rated } \\
\text { 'isolated' by no rater }\end{array}$ & $\begin{array}{c}\text { \% of abstracts rated } \\
\text { 'isolated' by all raters }\end{array}$ \\
\hline LEMM & 0.82 & $0 \%$ & $61 \%$ \\
PoS & 0.88 & $0 \%$ & $57 \%$ \\
VT & 3.44 & $12 \%$ & $9 \%$ \\
\hline
\end{tabular}

These results confirm our hypothesis that LEMM is more content isolated than VT. Contrary to our hypothesis, however, papers in PoS journals only scored marginally better than papers in LEMM journals for isolation. Thus, these results diverge from other research that focused on indirect isolation of philosophical research, i.e. between philosophy and other academic audiences (Chi \& Conix 2021). According to that research, research topics in PoS are substantially less isolated from other philosophical work and other research fields than topics in LEMM, and somewhat less isolated than topics in VT. The results of test 1 show that even if PoS papers are highly connected to other fields of academia, they are just as content isolated from the broader public as LEMM.

\footnotetext{
${ }^{5}$ For more information on the rating criteria, see supplementary materials, section $C$.

${ }^{6} \mathrm{~A}$ Kruskal-Wallis test showed that there are significant differences $(p<0.001)$ between LEMM, PoS and VT for these scores. A further Wicoxon rank sum test with continuity correction revealed a significant difference between PoS and VT, and between LEMM and VT (both $\mathrm{p}<0.001$ ).
} 


\subsection{Test 2: Uptake isolation based on PlumX metrics}

To complement the first test with a test for uptake isolation, we also analyzed altmetric data of philosophical journal articles. Altmetric measures include data from social media, blog posts, news outlets and other online venues. As such, they provide a direct way of measuring uptake-isolation and the impact of research beyond academia (Bornmann 2015; Moed 2017). Another advantage of these metrics is that they can be processed automatically and thus allow us to use a larger sample than for test 1 .

\section{Methods}

This test takes philosophical research topics as the unit of analysis. These topics are groups of documents with a single, narrow intellectual focus and produced by communities of around a hundred researchers (Klavans \& Boyack 2017). Examples of such research topics include 'the nature of models,' 'moral expressivism' and 'truthmakers.' For the selection and identification of philosophical research topics, we relied on the work of Chi and Conix (2021), who recently compared the academic isolation of POS, VT and LEMM by comparing citation and reference metrics of 6 PoS research topics, 6 VT topics and 5 LEMM topics. These research topics total 2,369 articles published between 2000 and 2017 and indexed in both Clarivate's Web of Science and PhilPapers (see Online resources, D). We chose this data period to allow all papers to have at least three years to accumulate citations in line with previous discussions on effective citation windows (Adams 2005; Chi 2016; Glänzel 2008; Wang 2013). By using the same research topics as Chi and Conix (2021) for the altmetric analysis, we can compare the results for uptake isolation with their results for philosophy's isolation from other academic fields.

For the altmetric measures we rely on data from Plum Analytics ${ }^{7}$, which provides insight into the ways people interact with individual pieces of research through five types of metrics: Usage, Captures, Mentions, Social Media, and Citations. Because we are only interested in the extent to which philosophical research reaches a non-academic audience, this study only relies on the Mentions and Social Media categories. The former includes blogs and online news outlets, the latter Twitter and Facebook (further details on these two metric categories are provided in Online resources, E).

As noted above, we hypothesized that (1) philosophical research is highly isolated and (2) that philosophical research in LEMM is more isolated than research in PoS and VT. Before testing these hypotheses we had to ensure that the two altmetric indicators that we use (i.e. Mentions and Social Media) do not simply track academic uptake. To enable a comparison between academic uptake of journal papers and the uptake of these papers beyond academia, we also included journal paper citation metrics from PlumX. Thus we downloaded the PlumX Metrics for 2,215 articles using pybliometrics, a Python wrapper for the Scopus API (Rose and Kitchin 2019). ${ }^{8}$ Note that all altmetric research faces the challenge of the low presence and density of social media altmetric counts among scientific publications, as reported in previous studies (Peters et al. 2017; Zahedi et al. 2014). Because

\footnotetext{
${ }^{7}$ https://plumanalytics.com/

${ }^{8}$ The data was downloaded on 8 September 2020, and included the PlumX altmetrics for all documents in the sample from Chi and Conix (2021) indexed in Scopus either by their DOI or Pubmed ID. Note that the sample in this study has 154 papers less than that in Chi and Conix' (2021), as not all papers from the latter are indexed in Scopus.
} 
of this high sparseness of the PlumX indicators we use (see Table 2), we aggregate the various indicators for each of the categories (Social Media and Mentions).

Table 2:The frequency of papers without any recorded values for the various PlumX altmetrics (2000-2017)

\begin{tabular}{|l|l|r|r|}
\hline \multirow{3}{*}{ Category } & Metric & \multicolumn{1}{l|}{$\begin{array}{l}\text { \# without } \\
\text { values }\end{array}$} & $\begin{array}{l}\text { \% } \\
\text { without } \\
\text { values }\end{array}$ \\
\hline \multirow{3}{*}{ Social Media } & Tweets & 1,884 & $85.1 \%$ \\
\cline { 2 - 4 } & Shares, Likes \& Comments & 2,053 & $92.7 \%$ \\
\hline \multirow{5}{*}{ Mentions } & References & 2,135 & $96.4 \%$ \\
\cline { 2 - 4 } & Blog Mentions & 2,186 & $98.7 \%$ \\
\cline { 2 - 4 } & News Mentions & 2,187 & $98.7 \%$ \\
\cline { 2 - 4 } & Q\&A Site Mentions & 2,202 & $99.4 \%$ \\
\cline { 2 - 4 } & Comments & 2,210 & $99.8 \%$ \\
\hline
\end{tabular}

\section{Results}

Correlations between online uptake and academic uptake

One may worry that altmetrics simply track academic uptake, as they may just reflect researchers using social media and other online channels to communicate with other researchers. We therefore tested the divergence between academic uptake and online uptake. The former was measured by traditional citation metrics (from PlumX, see Online resources E), and the latter by the PlumX Mention and Social media metrics. Given that the aggregated values of each metrics category are generated from different numbers of indicators and so are not directly comparable, we applied Spearman's rank correlation coefficient to assess the relationship among the three metrics through the paper rank instead of absolute values. Table 3 shows that the correlations among the three metrics are significant but rather weak. Although papers that were cited more often do correlate with being mentioned online more often, the low level of correlation indicates that the two online metrics reveal a different kind of uptake than citations. This result is in line with previous research on the correlation between citation and altmetric indicators (e.g., Costas et al. 2015; Zahedi et al. 2014). In addition, the Mention and Social Media metrics have a higher level of correlation between each other, showing the closeness between them compared to citations but still suggesting the independence of both these online metrics.

Table 3:Spearman's correlation coefficient among three metrics

\begin{tabular}{lccc} 
& Citation & Mention & Social Media \\
\hline Citation & & \\
Mention & $0.1408142 * * *$ & \\
Social Media & $0.1252303^{* * *}$ & $0.2005350 * * *$ & \\
\hline$* * * p<0.001$ & &
\end{tabular}


Online uptake

Having established that the measures of online and academic uptake are independent, we can focus on the former and use them to investigate the uptake isolation of POS, VT and LEMM. Most of the seven individual indicators of the Mention and Social Media metrics have no values for over $90 \%$ of all papers in the sample (see Table 2). Thus, we aggregated the indicators per category instead of analyzing individual indicators and limited the analysis to those papers with values for at least one indicator in both the Mention and Social Media categories. Table 4 shows how often papers in PoS, VT and LEMM appear on social media or are mentioned in online outlets such as blogs and news articles. Papers from LEMM tend to have lower online visibility than those from PoS and VT, in line with our hypothesis.

Table 4:All papers and papers with values for at least one metric in the three kinds of philosophy (2000-2017)

\begin{tabular}{|l|r|r|r|r|r|}
\hline \multirow{2}{*}{ Count } & All papers & \multicolumn{2}{|c|}{$\begin{array}{c}\text { Papers with a value for at } \\
\text { least one Mention metric }\end{array}$} & \multicolumn{2}{|c|}{$\begin{array}{r}\text { Papers with a value for at least } \\
\text { one Social Media metric }\end{array}$} \\
\cline { 2 - 7 } & Count & $\begin{array}{c}\text { \% in all papers } \\
\text { of the category }\end{array}$ & Count & $\begin{array}{c}\text { \% in all papers } \\
\text { of the category }\end{array}$ \\
\hline LEMM & 775 & 5 & $0.6 \%$ & 70 & $9.0 \%$ \\
\hline PoS & 747 & 64 & $8.6 \%$ & 164 & $22.0 \%$ \\
\hline VT & 847 & 64 & $7.6 \%$ & 168 & $19.8 \%$ \\
\hline
\end{tabular}

One might worry that these results are unreliable due to the high sparseness of the data. That is, it might be that the papers without data in each category swamp the high impact that some papers might have. If this effect differs between LEMM, POS and VT, it could bias the results. We therefore also calculated the average values of the Social Media and Mentions metrics for all the papers and for the papers that scored on at least one metric from each of these categories (call these impactful papers'). ${ }^{9}$ Figure 1 presents the differences between the mean values of all the papers in a field and just the impactful papers in the field for Mentions and Social Media. These differences show that there is indeed a strongly uneven distribution of online impact among philosophy papers. Because fewer papers were ever, and less frequently, mentioned in online outlets like blogs than on Twitter and Facebook, this difference is particularly strong for the Mentions category. Importantly, however, the results for these impactful papers are in line with the results for all papers: the papers in LEMM have lower online uptake, and hence are more isolated, than those in PoS and VT.

\footnotetext{
${ }^{9}$ The detailed values of each topic and kind of philosophy for the two groups of papers are listed in the supplementary materials (Online Resources D).
} 


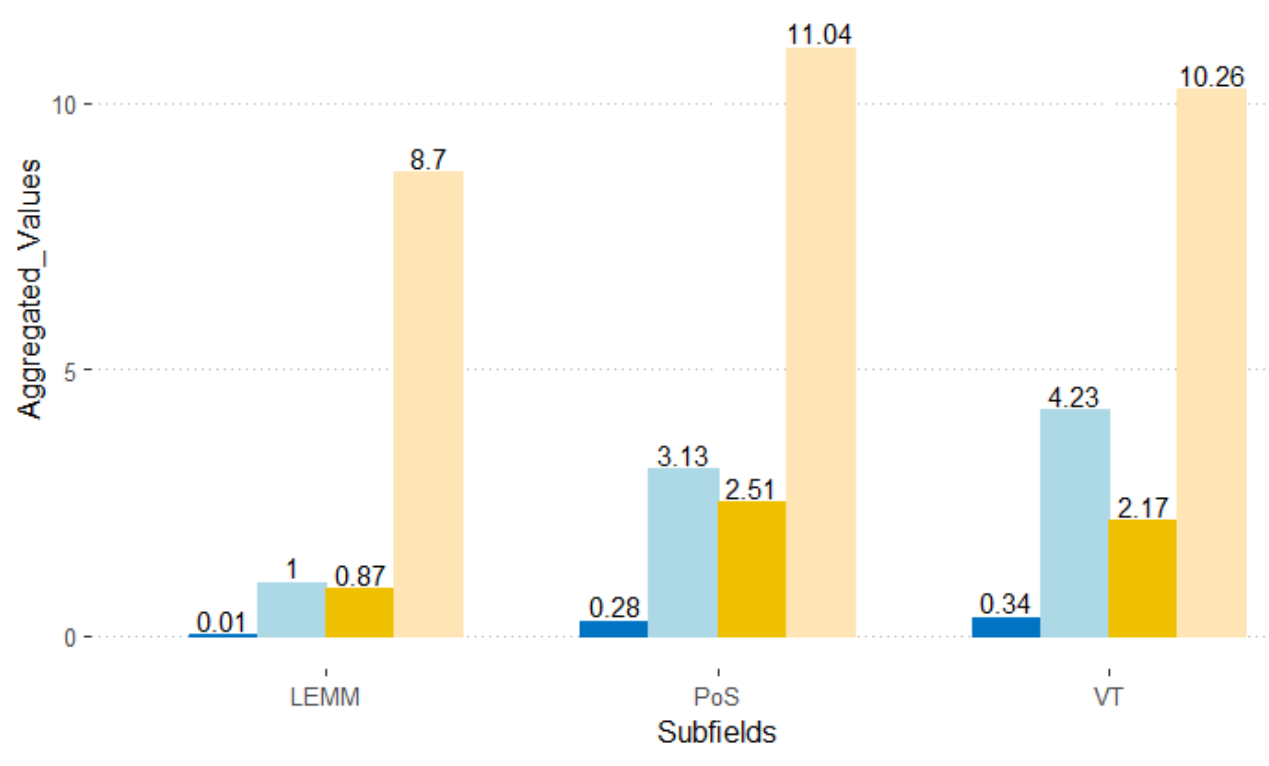

Figure 1:The average values of aggregated Mention and Social Media metrics (2000-2017)

\subsection{Conclusions empirical tests}

In section 2, we defined public relevance in terms of what would be chosen by an ideal democratic process. One might object that the measurements of isolation we introduced in this section fall short of fully capturing this notion. However, this is inevitable for any measure of something as complex as public relevance and does not imply that the results are meaningless. Still, there are several limitations worth emphasizing.

First, the documents we used for the test have important limitations. Test 1 relied only on abstracts and was limited to 328 papers. In addition, neither of the two tests considered philosophical books, which may play an important role in outreach. Second, the review criteria for test 1 are inevitably vague and leave some room for interpretation. We tried to control for this by using many raters (seven), and by selecting only raters with philosophical expertise such that they understand the abstracts and do not rate them as 'isolated' simply because they are highly specialized. Finally, test 2 relies on altmetric measures, which capture only a small part of the societal impact of academic research (Bornmann 2013; Pedersen et al. 2020; Reale et al. 2018). In particular, lay people influenced by philosophical ideas are unlikely to cite the paper when they discuss the ideas from that paper on social media or other outlets. While these limitations do not mean that the test results are meaningless, it is clear that they should be taken with caution.

Despite these limitations, we conclude that at least for these samples and measures both hypotheses are confirmed. First, the results of test 1 clearly suggest that the topics of much academic philosophy are content isolated from a non-academic public. This is confirmed by the sparseness of data in test 2, although these results are to be taken with care (see Bornmann 2014; Konkiel 2016). Hence, despite 
the sparseness of the altmetric data - between $85 \%$ and $99 \%$ of all papers had no values for the various indicators - we urge caution in interpreting the results of test 2 as definitive signs that all of philosophy is highly isolated. It should be noted, though, that this problem does not affect the comparison between POS, LEMM and VT, as we have no reason to assume that these limitations affect them differently.

Second, test 2 (uptake isolation) confirms the hypothesis that LEMM is more isolated than PoS and VT, with VT emerging as the least isolated kind of philosophy. Test 1 (content isolation) suggests that VT is clearly less content isolated than PoS and LEMM, but revealed no difference between PoS and LEMM. Thus, PoS and LEMM differed strongly in uptake isolation, but not in content isolation. This suggests that the two aspects of societal isolation are at least partially independent. It also suggests that disciplinary differences may play a role in uptake isolation. Papers in PoS are far more often published in science journals, and written by scientists, than papers in VT and LEMM (Chi and Conix 2021). If it is more common to communicate about one's research on social media and other online media in science than in philosophy, this would be reflected in uptake isolation but not in content isolation.

\section{The incentive structure of philosophy}

The empirical tests in the previous section suggest that philosophy is generally rather isolated, both with respect to its content and its uptake, from a broad non-academic audience. ${ }^{10}$ Previous research shows that at least some parts of philosophy (in particular LEMM) are also highly isolated from other academic fields (Chi and Conix 2021). Taking these together, it seems that the worries about the public relevance of philosophy mentioned at the beginning of the paper should be taken seriously: at least some substantial part of philosophy is rather isolated. Assuming that highly isolated philosophical research would likely not be allocated state funding based on an idealized democratic process, this is a problem. To resolve this problem, it is important to understand its causes: why is a lot of philosophical research isolated from the public?

Various studies show that publicly relevant research is typically done by researchers who are intrinsically motivated to do so (Holland 2016; Jaeger and Thornton 2006; O'Meara 2003, 2008). Moreover, there seems to be no lack of intrinsic motivation among philosophers, as survey research in a variety of subfields shows that philosophers are keen on doing publicly relevant research (Plaisance et al. 2019; Tiberius 2017). This suggests that other motivating factors trump philosophers' intrinsic motivation to do more publicly relevant work. This section focuses on extrinsic motivation and surveys the four main pillars of the incentive structure of academic philosophy: Review, promotion and tenure criteria (4.1); Publication and review practices (4.2); Research funding practices (4.3); and Academic awards (4.4). Based on this overview, we argue that the incentive structure of academic philosophy incentivizes philosophers to do research that is not publicly relevant. In the next sections ( 5 and 6 ), we will then draw on the literature on socially engaged philosophy as well as work in other fields to list various ways of making philosophy more publicly relevant.

\footnotetext{
${ }^{10}$ While altmetrics in other disciplines generally seem to have fewer papers without any data connected to it (and so by this test are less isolated, see e.g. Zahedi 2014), we are not making this claim, and the other claims in this paper, in a comparative sense. We think that it is a problem that philosophy is isolated, regardless of whether there are other disciplines with the same problem.
} 


\subsection{Review, promotion and tenure criteria}

The most formalized aspects of the reward structure of philosophy are the criteria for review, promotion, and tenure (RPT) that philosophy departments operate with. To date, there have been two studies that focus specifically on the RPT criteria used in philosophy departments. In the first, surveyed philosophy departments generally responded that with regards to tenure decisions, 'Interdisciplinary Experience,' 'Publishing in Non-Phil. Journals,' and 'Applied Research,' are considered but not important (Hrotic 2013). In the second, a vast majority of surveyed philosophy departments indicated that 'making the humanities accessible to the public' was either only marginally important or unimportant in tenure decisions (White et al. 2014). Other studies scrutinize RPT criteria more generally (Alperin et al. 2019; Schimanski and Alperin 2018). This research too shows that the most important method of evaluating scholarly output is one's publication record, the quality of which is determined mainly by the prestige of the publication venues and impact factors that measure use within a scholarly domain (Acker and Webber 2016; Green and Baskind 2007; Macfarlane 2007).

There is typically no independent condition for faculty to produce research output that is publicly relevant (Alperin et al. 2019). Many RPT documents do require public engagement as well and mention the value of disseminating one's work beyond the walls of academia. Yet these guidelines tend to be defined less formally and so are harder to evaluate than those spelling out the required research output (Darling et al. 2013; Piwowar 2013). One study that analyzes the significance of the public dimension of faculty work based on 864 RPT documents, concludes that these documents "signal that faculty should focus on uptake within their specific academic fields" and that since "faculty careers are more closely scrutinized through metrics that seek to reflect research use and value within academia [...], the ability for faculty to dedicate time and energy into activities that more directly serve the public good are not incentivized" (Alperin et al. 2019, p. 17).

That career success is largely determined by scholarly outputs that are relevant for one's peers is also reflected in the type of metrics that are predictive of success on the academic job market. One study, for example, considered 25,604 individual scientists in PubMed, only $6.2 \%$ of which eventually made it to Principal Investigator (van Dijk et al. 2014). This variation in success was largely predictable by publication record, using metrics like numbers of first-authored papers, impact factors of the journals, and citation numbers (ibid.). Although this research is correlational and not causal, it is indicative of the type of scholarly output that is primarily rewarded. There is in our opinion no reason to think philosophy is different in this regard than other academic fields. While philosophers can often be heard saying that they value relevance and communication outside one's research community, it is unclear whether they also reward it when they evaluate other philosophers. Survey research found relatively low support for the claim that publications in non-philosophy journals should be given equal weight in RPT decisions (Tiberius 2017). In line with this, many philosophers of science indicated in another survey that the discipline of philosophy of science does not reward disseminating one's work outside of philosophy (Plaisance et al. 2019).

As RPT criteria mostly incentivize publishing in journals, they likely contribute to philosophy's isolation and hence lack of public relevance. They most obviously increase uptake isolation, as top journals in philosophy are primarily aimed at philosophers, and non-philosophical publication venues are disincentivized. To the extent that these top journals also incentivize research that is content-isolated (see below), RPT criteria also encourage research on topics that are not publicly relevant. 


\subsection{Publication practices and review}

The weight of journal publications in RPT criteria highlights the crucial role journal publications play in academic success and suggests they lie at the core of the incentive structure of philosophy. Journals are particularly important because they directly control the dissemination of research. Depending on the audience they target, they could make philosophy more uptake isolated (if they aim at philosophers), or less uptake isolated (if they aim at a broad audience). Given the specialized nature of academic journals, however, their influence is more likely to affect content isolation: By selecting manuscripts based on the public relevance of the topic, they can determine the content isolation of philosophy. This could work both directly and indirectly. If the editorial preferences of philosophy journals were to select for publicly relevant research, then typical RPT criteria would thereby reward this type of research output indirectly. This way, editorial practices could incentivize philosophical research that is not content isolated.

However, given that relatively few of the papers from the journals we scored are explicit about the public relevance of the presented research in the abstract (see section 3.1), it appears that top journals in philosophy do not incentivize publicly relevant research. Of course, philosophical research could be publicly relevant without this being clear from the abstract of the paper, which we used to determine the relevance of the paper as such. However, assuming that researchers include their most important contributions in the abstract of their paper, it is telling that so few were rated as not content isolated. This suggests that philosophers consider the acceptance of their paper to depend on its relevance for the academic field, as judged by their peers, rather than on its relevance for non-philosophers. As an exception, we should mention here that there are several journals whose explicit goal is to publish publicly relevant philosophy. ${ }^{11}$ These are, however, a clear minority.

That authors of papers in academic philosophy expect the acceptance of their paper to depend on the paper's relevance for their peers is probably justified, given the nature of peer review. Yet to determine whether this is really the case, we also surveyed the scope, aims and reviewer instructions of 57 major philosophical journals (see Online resources, $\mathrm{G}$ for a list of the journals) to see if they take public relevance into account when considering papers for publication. More precisely, we collected publicly available information on the scope and aims of the journal on the journals' websites, and contacted the editors or editorial assistants (with one follow-up email) to ask for the instructions that are given to reviewers and for the criteria they ask editors to take into account when evaluating manuscripts.

Of the 56 journals we contacted, 39 responded. Few of these journals (8/39) provide reviewers or editors with one or more explicit criteria. Only one of these included public relevance among the criteria, namely (and not surprisingly), Journal of Applied Philosophy. Instead, criteria like clarity, rigor, size of contribution, argumentative strength, and connection to existing literature and debates were far more common. Considering the journals' aims and scopes, only 10 journals included statements that could be interpreted as aiming to avoid uptake isolation $(7 / 56)$ or content isolation $(8 / 56)$.

The study of the aims, scope and review criteria of 56 of philosophy's top journals shows that publicly relevant philosophy is not incentivized by these journals. Instead, these journals mostly incentivize

\footnotetext{
${ }^{11}$ For example, the Public Philosophy Journal, the Journal of Applied Philosophy, Philosophy \& Public Affairs, and the Journal of Public Philosophy.
} 
research that is rigorous, clear, builds on existing literature, and makes a substantial contribution to existing debates.

Other ways in which review and publication practices may affect the public relevance of philosophy are harder to test. We do not take them into account in our evaluation but mention them here as future lines of research. One of these concerns the combination of peer review practices and the low acceptance rates of philosophy journals. Given these low acceptance rates, reviewers and editors may be highly critical and tend to look for reasons to reject papers. This encourages authors to write safe papers that make rather small points and do not diverge too much from the style of other papers that get published. If writing publicly relevant philosophy is not the dominant style, this would discourage authors to try and change that. Similarly, if it is easier to find argumentative weaknesses in practically oriented papers than in highly abstract, technical papers - for example, because of the complexities of practical problems - then low acceptance rates discourage writing practically oriented papers. Dennett (2006, p. 40) discusses a similar mechanism in the Chmess-paper we cited above:

"[Y]ou see that somebody eminent has asserted something untenable or dubious in print; Professor Goofmaker's clever but flawed piece is a sitting duck, just the right target for an eyecatching debut publication. Go for it. You weigh in, along with a dozen others, and now you must watch your step, because by the time you've all cited each other and responded to the responses, you're a budding expert on How to Deal with How to Deal with Responses to Goofmaker's minor overstatement."

Most professional philosophers are familiar with the cottage industries of papers that Dennett refers to here. It is unclear how and if publication practices contribute to this; perhaps reviewers are more likely to give positive reviews if the paper deals with a subject they also work on, or perhaps it is because journals encourage contributions that build on existing work in the field.

Even if we disregard these mechanisms, it seems clear that publication practices disincentivize publicly relevant work. They increase uptake isolation because they target mostly academic audiences. More importantly, they also seem to increase content isolation through their aims, scope, and criteria for review. Their effect is then reinforced by RPT criteria, which strongly value journal publications.

\subsection{Research funding}

Philosophical research typically requires grants to pay junior staff, travel costs and research materials. In addition, successful grant applications often play a role in RPT criteria. Hence, methods for distributing research funding constitute another important part of the incentive structure of philosophy. Unlike the journals just considered, these funding mechanisms do seem to encourage publicly relevant philosophy. In the first place, these funding mechanisms target content isolation. A rapidly increasing number of funding bodies now includes 'societal impact' as one of its evaluation criteria (Holbrook \& Frodeman 2011; Langfeldt \& Scordato 2016). However, there is no clear empirical evidence that this is an effective strategy. Indeed, some scholars argue that the vagueness of this notion as well as the difficulty of evaluating it are likely to make review unreliable (e.g., Rip 2000). It may also be that applicants promise to do publicly relevant work but do not follow up on this if the grants are successful. The results of study 1 (content isolation) are at least consistent with the cynical 
view that philosophers advertise their prospective work as being of public relevance even though their published journal articles are not.

In addition, and despite the efforts of funding bodies to increase societal impact, it may well be that current methods of distributing funding in philosophy even discourage public relevance. This is because peer review of grant proposals tends to be conservative (i.e., discouraging innovation) (Heinze 2008; Gillies 2014). Because it seems currently relatively uncommon to pursue strong societal impact in philosophy, the use of peer review may discourage philosophers to apply with innovative projects with high societal impact. Such suppression of societally relevant work by other, dominant paradigms in philosophy may even have already occurred through the policies of the National Science Foundation's 'history and philosophy of science' program in the 1950s and 1960s (Vaesen and Katzav 2019).

Funding mechanisms also incentivize communication with a broad audience, thus decreasing uptake isolation. For example, many grant schemes require applicants to provide a plan of how they will communicate the results of their research to a broader community. Funding bodies are also likely to be an effective driving force behind recent changes in dissemination practices in academia, often requiring the published research to be open access. Perhaps as a result of this, work in the humanities is published in some form of open access increasingly often (Piwowar et al. 2018). This means that scholarly work from the humanities is now more than ever openly accessible to lay people. At the same time, however, Alperin et al. (2019) report that open access publishing remains low on the priority lists of faculty because traditional publishing is better for one's career (see also Gaines 2015). Hence whereas funding agencies incentivize open access publishing, expectations about the (un)importance of this in RPT procedures at the same time disincentivize it (Niles et al. 2020).

\subsection{Academic awards}

A final factor that might incentivize philosophers to do publicly relevant work is academic awards, some of which are very prestigious and carry a considerable cash prize. Of the biggest of such prizes, many explicitly aim to award philosophical work that deals with publicly relevant topics. The Berggruen Prize for Philosophy and Culture, for instance, awards a 1 million dollar prize 'for major achievements in advancing ideas that shape the world' (See also Kyoto Prize in Thought and Ethics and Meister Eckhart Prize and Online Resource $\mathrm{H}$ for a list of important awards in philosophy). Yet despite the prestige and considerable prize money associated with these awards, we expect that they have little impact in actually incentivizing publicly relevant philosophy. Since any one philosopher has such a small chance of winning one of these prizes, we expect that professional philosophers for the most part adjust their activities and resources in response to the reward system associated with RPT criteria, publication practices, and funding mechanisms.

\subsection{Incentive structure: conclusion}

Of the components of the incentive structure listed here, only some aspects of securing research funding and academic awards plausibly encourage philosophers to do publicly relevant research. RPT criteria and publication practices, on the other hand, clearly encourage philosophers to do research primarily aimed at other philosophers. Assuming the weight of RPT criteria and journal publications 
to be far stronger than that of awards and even funding, this suggests that the incentive structure of philosophy is likely an important driver behind work in philosophy that is not publicly relevant.

Let us, before we continue, take stock of the paper so far. Over the previous sections, we have provided empirical support for the popular claim that philosophical research is often not publicly relevant (i.e., isolated), and that this is undesirable because philosophy is largely publicly funded. We have argued that the incentive structure of philosophy is likely to be an important cause of this problem. In the remainder of this paper, we discuss a range of solutions for this problem. For these solutions, we start from two general principles suggested by the previous sections.

First, because LEMM tends to be more isolated than PoS and VT, one way of making philosophy more publicly relevant is to shift philosophical effort from LEMM to work in PoS and VT. Note that we do not mean to argue that LEMM should be replaced by PoS and VT. Rather, we argue that the balance is off and should be shifted: while currently LEMM dominates PoS and VT, we should move to a distribution of research effort where research in PoS and VT outnumbers foundational work in LEMM. Such foundational work may well be necessary to enable good PoS and VT, and without it the latter could be reduced to mere commentary on social issues without any particular expertise. ${ }^{12}$ However, LEMM should not dominate PoS and VT if we want philosophy to be publicly relevant. The solutions we discuss below are thus meant to change the relative proportion of applied and fundamental work, not to entirely abolish the latter.

Second, solutions to the problem of isolation in philosophy should try to change the incentive structure of philosophy. This should not be taken to mean that individual-level changes are not important. There is a strong movement in philosophy towards publicly engaged work and we think that such individual-level changes are a crucial part of the solution (Nguyen 2019). However, we argue that they should be complemented by direct changes in the incentive structure as well. We discuss individual-level changes in section 5 and incentive-level changes in section 6 .

\section{Solutions I: Individual changes}

We are, of course, not the first to make suggestions about how philosophy can be made more publicly relevant. There is a well-established and rapidly growing movement in philosophy trying to bring it closer to the world out there, and philosophers keen to have an impact can build on a wide range of existing initiatives and approaches. Under different names such as 'public philosophy,' 'field philosophy, ' '(socially) engaged philosophy of science' and 'socially responsible philosophy of science,' philosophers are increasingly trying to have a direct impact with their work (see, among many others, Brister \& Frodeman 2020; Cartieri \& Potochnik 2014; Fehr \& Plaisance 2010; Frodeman \& Briggle 2016; Frodeman 2017; Plaisance \& Elliott 2020). This has resulted in various organizations devoted to this aim, as well as a range of strategies, guidelines and interesting case studies that can help philosophers hoping to have an impact with their work (Hicks \& Holbrook 2020; Nguyen 2019).

Barring a few exceptions (which we discuss in section 6), all solutions proposed by these papers and initiatives are ways in which individual philosophers can change their behaviour to do more relevant

\footnotetext{
12 Though some would argue that this is in line with what philosophy should aim to be (Frodeman \& Briggle 2016).
} 
work or enable others to do more relevant work. One common suggestion is to improve the recognition of publicly relevant philosophy, for example with designated awards or simply by advocating its importance in public (Burroughs 2020; Plaisance et al. 2019; Tiberius 2017). Another common suggestion is to implement publicly relevant philosophy into undergraduate teaching, or organize designated workshops or courses to teach graduate students and faculty how to do publicly relevant philosophy (O'Meara \& Jaeger 2006; Plaisance et al. 2021; Tiberius 2017). There are now ample case studies, practical suggestions and even general frameworks available that can serve as starting points for such courses or philosophers trying to change their work (see in particular Plaisance \& Elliott 2020). In addition, philosophers wanting to do publicly relevant work can try to collaborate with one of the many societies and initiatives that already exist, and the Public Philosophy Network even offers a mentoring service for university faculty who want to implement their publicly relevant work in their promotion or tenure files. ${ }^{13}$

Unfortunately, however, there is very little empirical research that tells us which of these strategies is most effective. From the little empirical research that exists, at least one clear lesson emerges: impactful work typically requires direct involvement of stakeholders and end-users throughout the research project. Thus, rather than simply communicating research findings to non-academic audiences (or researchers from different disciplines), they should be part of the knowledge generation and design of the research (Aiello et al. 2020). Similarly, a qualitative study by Plaisance et al. (2021) found that direct, face-to-face interactions were the main pathway for philosophers of science to have a broader impact. These findings are interesting, as engaged scholarship very often consists in communicating one's findings to policymakers and a lay audience, rather than in a collaboration with these groups (Saltmarsh et al. 2009).

In addition, Aiello et al.'s (2020) survey of high-impact research in the social sciences and humanities shows that two other strategies are particularly effective for researchers wanting to do publicly relevant work. First, research with substantial societal impact typically has an active and explicit strategy for achieving it. This means that one should not simply think about disseminating one's research to lay communities once the research is done. Rather, such dissemination, along with other forms of engagement, should be part of the research project from the start (Plaisance \& Elliott 2020). And second, impactful work in the humanities and social sciences is typically evidence-based. One way of increasing the potential impact of one's research, then, would be to implement empirical methods along with more traditional methods like conceptual analysis (Pence \& Ramsey 2018).

These individual solutions are a matter of responsibility and willingness. However, a change of culture relying solely on intrinsic motivation is unlikely to resolve the problem of philosophy's isolation fully. First, turning around the discipline's culture is likely to be very hard. Studies show that disciplines engaged in pure research and 'soft scholarship' (in contrast with the hard sciences) are generally the least likely to pursue engaged research (Doberneck \& Schweitzer 2017). In addition, researchers of color and women tend to engage more often in engaged research than white men (Antonio 2002; Antonio et al. 2000; Baez 2000; Demb \& Wade 2012; O'Meara 2003), and philosophy is still dominated by the latter (Dotson 2013). ${ }^{14}$

\footnotetext{
${ }^{13}$ https://www.publicphilosophynetwork.net/resources

${ }^{14}$ For recent numbers on diversity in philosophy, see Schwitzgebel (2020).
} 
Second, the individual-level changes that are discussed - selecting publicly relevant topics, changing dissemination practices, etc. - go against the current incentive structure of philosophy. Hence, many philosophers probably cannot afford to make such changes if they want to meet tenure conditions or bolster their publication record. ${ }^{15}$ Indeed, survey research shows that philosophers generally value engaged research and communication with a broad audience (Plaisance et al. 2019; Tiberius 2017). This means that they are already intrinsically motivated to pursue such research but that extrinsic motivations are often simply stronger. This is confirmed by the fact that scholars typically choose engagement activities that take up little time, and that they indicate that increasing engaged scholarship's weight in RTP criteria is the best way to encourage it (Demb \& Wade 2012; Hinck \& Brandell 2000). This is what Burroughs $(2020$, p.3) calls 'the problem of two lives': juggling "both the traditional requirements for employment and advancement in their institution [...] alongside the time and energy-intensive work required to develop public philosophy project(s)." Because of this problem of two lives, fulfillment of the impact agenda is unlikely if the dominant incentive structures in academia do not reward engaged scholarship or penalize isolated research. ${ }^{16}$ This means that making philosophy more publicly relevant requires changing the incentive structure of philosophy.

\section{Solution II: Changing the incentive structure}

Large-scale individual change in behavior is only likely to occur if there is no cost to it or if it also benefits philosophers in other ways than the mere satisfaction one gets from having a societal impact. In this section, we discuss changes to RPT criteria, publication practices, and funding mechanisms that could facilitate such large-scale individual change. These changes are harder to effect than those discussed in section 5. This might explain why these incentive-level changes - apart from those discussed in 6.1 - generally get little attention in the literature on publicly relevant philosophy. For the same reason, the solutions we discuss come with a caveat: the incentive system of academia is complex and changing it to encourage publicly relevant work might affect various other aspects of academic work. This means that the solutions we discuss may have unwanted side effects. We try to point to these briefly where they are foreseeable, but it is clear that such effects are often hard to predict.

We should also note that we limit our discussion to solutions that are relatively easy to realize. For example, we agree with Frodeman and Briggle (2016) that one way of making philosophy more publicly relevant would be to hire philosophers at institutions specialized in the domains that these philosophers can be of relevance for, rather than at designated philosophy departments. However, we do not see a realistic path towards such drastic institutional change and have therefore omitted it from our discussion.

\subsection{RPT criteria and institutional changes}

\footnotetext{
${ }^{15}$ There are of course individual-level changes that philosophers can make at no cost. In their role as reviewers, philosophers exert some influence on the kinds of papers that get published. Given that journals mostly let reviewers choose which criteria to base their judgement on, they are free to take public relevance into consideration in deciding whether a paper should be published.

${ }^{16}$ See also Wittkower et al. (2013) and Moher et al. (2018) and the statement of the APA on public philosophy: https://www.apaonline.org/page/publicphilosophy
} 
One obvious way in which institutional change could facilitate publicly relevant philosophy is by hiring researchers that do publicly relevant work. The tests in section 3 suggest that one good strategy here is to hire more philosophers that focus on topics in POS and VT and fewer philosophers specializing in LEMM. Such a change in hiring practices would not only produce more publicly relevant work but would also incentivize philosophers looking for a job to do such work.

More generally, philosophy departments could reward publicly relevant scholarship through the RTP criteria they utilize (Burroughs 2020; Plaisance et al. 2021; Tiberius 2017). Most obvious here is including clear and formal criteria for impact, similar to the citation and publication metrics that are already commonly used. Another option is to include professional practice portfolios (with e.g. letters from community members) as a requirement in tenure or promotion files (Burroughs 2018). The downside of the former is that altmetrics, like all metrics, do not always capture what we are after, are susceptible to gaming, and come with an administrative cost (Pedersen et al. 2020). The downside of the latter is that such portfolios are not as clear a target as traditional metrics used for evaluation and hence may be less effective in changing researchers' behavior. It is therefore important to complement any new criteria with a system to document as many forms of publicly relevant philosophy as possible (Sandmann et al. 2008). Another way to ensure that various dimensions of publicly relevant work are captured is to involve non-academic stakeholders in the review procedures of tenure and promotion files (Burroughs 2020).

Institutions can also provide seed funding and incentive grants for engaged work. These are likely to be effective because, as we indicate below, traditional peer-reviewed project funding may well disincentivize engaged work. Hence, dedicated impact-oriented grants may lift an important barrier to doing engaged research (Ward 1998). Indeed, researchers indicated in a survey by Demb and Wade (2012) that new grants for engagement would be the most effective way to increase engagement activities.

Unfortunately, empirical research on the efficacy of these measures is scarce. However, the little research that exists suggests that these institutional changes are effective. In a large survey study by O'Meara and colleagues (O'Meara 2005), the Chief Academic Officers of institutions who implemented these changes recently were significantly more likely to report an increase in publicly relevant scholarship than their colleagues at universities that did not adopt such policies. More precisely, they reported an increase in chances to get tenure or promotion based on public engagement, an increase in the proportion of tenure and promotion files that emphasize such engagement, and an increase in the impact of the research on the local community and state ( $O$ 'Meara 2005). Interestingly, academic officers at institutions with impact-oriented policies were also more likely to report an increase in the overall satisfaction of faculty with the reward system (O'Meara 2006).

\subsection{Changing publication practices}

Because journal publications are the main currency of prestige in philosophy, and thus play an important role in hiring, promotion, and tenure conditions, they provide very effective means to intervene in the kinds of work philosophers do. That is, if journal publications require societally impactful work, then philosophers are likely to do such work. 
Because peer review is the main mechanism used for deciding which research gets published, changes to peer review are likely to be most effective. Like for grant review, one solution could be to use nondisciplinary reviewers as a way of evaluating societal impact. This is likely to be effective because it would discourage research that is highly isolated or aimed at a very small research community. As many journals in philosophy of science regularly invite scientists to review philosophical papers, this is already common practice. There is, as far as we know, only one philosophical journal that currently uses a 'community' reviewer in a process of formative peer review. In this process, an academic and a community reviewer support a paper through its development and ensure that it meets the criteria of accessibility and relevance (among others). ${ }^{17}$ Of course, even though this journal shows that community reviews are possible, more research would be needed to investigate this strategy's efficacy, practical difficulties and other downsides.

An alternative to changing the reviewers would be to change the criteria for review. As we discussed above, most journals in philosophy have no explicit list of criteria and any criteria we could find typically did not include public relevance or related notions. An easy way to incentivize societally relevant work, then, would be to adopt an explicit list of criteria and give enough weight to criteria like public relevance and how broad the potential readership of a paper is. Finally, philosophy could be made more accessible to the broader public by making publications more accessible (e.g., through Open Access). However, we are afraid that this would only be effective if there are also fewer papers that are content isolated.

\subsection{Changing publication practices}

Because many philosophers rely on funding agencies to finance their research, these agencies exert a strong influence over the kinds of research that philosophers can do. Thus, one way to encourage philosophers to have a societal impact is to adapt the way these funders distribute their resources. Once again, one effective strategy in philosophy would be to shift funding from LEMM to PoS and VT, for example by dedicated grants. The potential efficacy of a dedicated funding campaign is illustrated by the way the practices in the National Science Foundation's 'history and philosophy of science' program in the 1950's shifted funding away from value-laden approaches to philosophy (Vaesen \& Katzav 2019).

In addition to dedicated calls, general changes in funding mechanisms too could incentivize publicly relevant philosophy. Currently, a large proportion of these resources is distributed through peerreviewed project funding, and various common strategies to incentivize impact consist in minor changes to this method. As discussed above, many funding bodies attempt to increase public relevance by including it in the criteria for peer review of grant proposals, but it is unclear whether that strategy is effective. One of the main worries is that most academics have little expertise on societal impact and so are in a bad position to evaluate it. ${ }^{18}$ One way to address this problem is to make peer review transdisciplinary and interdisciplinary, that is include both impact experts and societal stakeholders in the review process (Frodeman \& Briggle 2012; Holbrook \& Hrotic 2013). This has the added benefit of making the review process more democratic. Impact is, after all, at least

\footnotetext{
17 The journal in question is the Public Philosophy Journal, see https://publicphilosophyjournal.org/instructions-for-participants/

18 Though, interestingly, they seem confident of their judgement (Holbrook and Hrotic 2013).
} 
partially a matter of judging what is important for society, and the inclusion of laypeople would mean that a larger diversity of value-judgements is represented. Pre-review training could then be used to calibrate these various reviewers and increase inter-rater reliability (Derrick \& Samuel 2017). Various funding bodies already include such non-disciplinary reviewers but no large-scale empirical research on the efficacy of this strategy has been done so far (Frodeman \& Briggle 2012).

Funding agencies can also intervene at other stages of the funding process. For example, many funding bodies try to encourage societal impact by putting it in the eligibility criteria and grant calls. This can range from asking user input in designing grant calls, to encouraged or required collaboration with users while developing the grant or even a list of societal partners and hard requirements for collaboration with such partners (Arnott et al. 2020).

A more radical option for change would be to replace peer review of grant proposals with alternative funding methods, such as lotteries (Fang \& Casadevall 2016) and baseline funding (Vaesen \& Katzav 2017). There is a growing body of research that suggests that these methods of distributing funding are epistemically and ethically desirable, although it is hard to predict the effect that drastic changes would have (Guthrie et al. 2018). The point here is that these alternative methods may be more effective choices to enable impactful philosophy as they are unlikely to be conservative and give researchers the freedom to diverge from established standards and paradigms. Again, however, there is no empirical research that confirms this.

While all these solutions are promising and are being implemented increasingly often, it is unclear how effective they are given that empirical studies are lacking (Holbrook \& Hrotic 2013). Hence, the main solution here is second-order: funding bodies should use the data they have to evaluate which strategies are best to foster societal impact and to identify potential downsides of all strategies (see also Moher et al. 2018). As increasingly more sophisticated tools for measuring such impact are being developed, funding bodies could launch experimental calls in order to, ultimately, fine-tune their methods of distribution to their aim of funding research with societal impact.

\section{Conclusions}

This paper has provided empirical evidence that philosophical research, and LEMM in particular, is often isolated from the broader public and in that sense lacks public relevance. We think this is a problem because philosophy is publicly funded. Solving this problem requires trying to change individual behavior but more importantly also the incentive structure of philosophy. We have discussed a range of individual-level and incentive-level changes that could be used to do this. While we realize that many of these solutions are likely to meet strong resistance or are hard to implement, we hope that they can serve as a starting point for further debate and can contribute to making academic philosophy more publicly relevant.

\section{Acknowledgements}

Stijn Conix gratefully acknowledges funding from the Flemish Research Council (FWO; Grant No. 3H200026). Olivier Lemeire gratefully acknowledges funding from the Flemish Research Council (FWO; Grant No. 12S0220N). We also thank Alexander Michael Witkamp, Alejandro Gordillo García, Phyla Kupferschmidt, Dashan Xu and Samuel Sheldon Laves for rating the abstracts for study 1. 


\section{$\underline{\text { References }}$}

Acker S, Webber M (2016) Discipline and Publish: The Tenure Review Process in Ontario Universities. In: Shultz L, Viczko M (eds) Assembling and Governing the Higher Education Institution: Democracy, Social Justice and Leadership in Global Higher Education. Palgrave Macmillan UK, London, pp 233-255.

Adams J (2005) Early citation counts correlate with accumulated impact. Scientometrics, 63(3): 567581.

Aiello E, Donovan C, Duque E, et al (2020) Effective strategies that enhance the social impact of social sciences and humanities research. Evidence \& Policy: A Journal of Research, Debate and Practice 17(1):131-146. https://doi.org/10.1332/174426420X15834126054137

Alperin JP, Muñoz Nieves C, Schimanski LA, et al (2019) How significant are the public dimensions of faculty work in review, promotion and tenure documents? elife 8:e42254. https://doi.org/10.7554/eLife.42254

Antonio AL (2002) Faculty of Color Reconsidered: Reassessing Contributions to Scholarship. The Journal of Higher Education 73:582-602. https://doi.org/10.1353/jhe.2002.0043

Antonio AL, Astin HS, Cress CM (2000) Community Service in Higher Education: A Look the Nation's Faculty. The Review of Higher Education 23:373-397. https://doi.org/10.1353/rhe.2000.0015

Arnott JC, Kirchhoff CJ, Meyer RM, et al (2020) Sponsoring actionable science: what public science funders can do to advance sustainability and the social contract for science. Current Opinion in Environmental Sustainability 42:38-44. https://doi.org/10.1016/j.cosust.2020.01.006

Baez B (2000) Race-related service and faculty of color: Conceptualizing critical agency in academe. Higher Education 39:363-391. https://doi.org/10.1023/A:1003972214943

Bornmann L (2015) Alternative metrics in scientometrics: a meta-analysis of research into three altmetrics. Scientometrics 103:1123-1144. https://doi.org/10.1007/s11192-015-1565-y

Bornmann L (2014) Do altmetrics point to the broader impact of research? An overview of benefits and disadvantages of altmetrics. Journal of Informetrics 8:895-903. https://doi.org/10.1016/j.joi.2014.09.005

Bornmann L (2013) What is societal impact of research and how can it be assessed? a literature survey. Journal of the American Society for Information Science and Technology 64:217-233. https://doi.org/10.1002/asi.22803

Brister E, Frodeman R (2020) A Guide to Field Philosophy: Case Studies and Practical Strategies. Routledge.

Burroughs, M (2020) Supporting Public Philosophy: Two Lives and Three Strategies. Public Philosophy Journal, 3(2).

Burroughs, M (2018) How to survive a crisis: reclaiming philosophy as a public practice. Palgrave Communications, 4(1), 1-5. https://doi.org/10.1057/s41599-018-0163-z

Cartieri F, Potochnik A (2014) Toward Philosophy of Science's Social Engagement. Erkenntnis 79:901-916. https://doi.org/10.1007/s10670-013-9535-3

Chi PS, Conix S (2021) Measuring the Isolation of Research Topics in Philosophy. Preprint archived at http://philsci-archive.pitt.edu/19083/. 
Chi PS (2016) Differing disciplinary citation concentration patterns of book and journal literature? Journal of Informetrics 10(3): 814-829.

Costas R, Zahedi Z, Wouters P (2015) Do "altmetrics" correlate with citations? Extensive comparison of altmetric indicators with citations from a multidisciplinary perspective. Journal of the Association for Information Science and Technology 66:2003-2019. https://doi.org/10.1002/asi.23309

Darling ES, Shiffman D, Côté IM, Drew JA (2013) The role of twitter in the life cycle of a scientific publication. arXiv:13050435 [physics, q-bio]

Demb A, Wade A (2012) Reality Check: Faculty Involvement in Outreach \& Engagement. The Journal of Higher Education 83:337-366. https://doi.org/10.1353/jhe.2012.0019

Dennett DC (2006) Higher-order truths about chmess. Topoi 25:39-41. https://doi.org/10.1007/s11245-006-0005-2

Derrick G, Samuel G (2017) The future of societal impact assessment using peer review: preevaluation training, consensus building and inter-reviewer reliability. Palgrave Communications 3:1-10. https://doi.org/10.1057/palcomms.2017.40

Doberneck DM, Schweitzer JH (2017) Disciplinary Variations in Publicly Engaged Scholarship: An Analysis Using the Biglan Classification of Academic Disciplines. JHEOE 21:78-103

Dotson, K (2013) "How is this paper philosophy?." Comparative Philosophy 3(1): 121-121.

Fang FC, Casadevall A (2016) Research Funding: the Case for a Modified Lottery. mBio 7:e00422-16. https://doi.org/10.1128/mBio.00422-16

Fehr C, Plaisance K (2010) Socially relevant philosophy of science: an introduction. Synthese 177:301-316. https://doi.org/10.1007/s11229-010-9855-7

Frodeman R (2017) The impact agenda and the search for a good life. Palgrave Communications 3:16. https://doi.org/10.1057/palcomms.2017.3

Frodeman R, Briggle A (2016) Socrates Tenured: The Institutions of Twenty-first-century Philosophy. Rowman \& Littlefield International.

Frodeman R, Briggle A (2012) The Dedisciplining of Peer Review. Minerva 50:3-19. https://doi.org/10.1007/s11024-012-9192-8

Gaines AM (2015) From Concerned to Cautiously Optimistic: Assessing Faculty Perceptions and Knowledge of Open Access in a Campus-Wide Study. Journal of Librarianship and Scholarly Communication 3(1). http://dx.doi.org/10.7710/2162-3309.1212

Gillies D (2014) Selecting applications for funding: why random choice is better than peer review. RT A Journal on Research Policy and Evaluation 2(1). https://doi.org/10.13130/2282-5398/3834

Glänzel W (2008) Seven myths in bibliometrics. About facts and fiction in quantitative science studies. In: Kretschmer H \& Havemann F (Eds.), Proceedings of WIS 2008. Germany, Berlin pp. 1-10

Green RG, Baskind FR (2007) The second decade of the faculty publication project: Journal article publications and the importance of faculty scholarship. Journal of Social Work Education 43:281-295

Guthrie S, Ghiga I, Wooding S (2017) What do we know about grant peer review in the health sciences?. F1000Research, 6.

Heinze T (2008) How to sponsor ground-breaking research: A comparison of funding schemes. Sci Public Policy 35:302-318. https://doi.org/10.3152/030234208X317151

Hicks D, Holbrook JB (2020) A Cartography of Philosophy's Engagement with Society. Minerva 58:2545. https://doi.org/10.1007/s11024-019-09384-3 
Higgins A, Smith B (2013) A Citation Based View of the Ontology Community in Philosophy. In Proceedings of the ACM Web Science 2013.

Hinck S, Brandell ME (2000) The Relationship between Institutional Support and Campus Acceptance of Academic Service Learning. American Behavioral Scientist 43:868-881. https://doi.org/10.1177/00027640021955522

Holbrook JB, Frodeman R (2011) Peer review and the ex ante assessment of societal impacts. Res Eval 20:239-246. https://doi.org/10.3152/095820211X12941371876788

Holbrook JB, Hrotic S (2013) Blue skies, impacts, and peer review. RT A Journal on Research Policy and Evaluation 1(1). https://doi.org/10.13130/2282-5398/2914

Holland BA (2016) Factors and Strategies That Influence Faculty Involvement in Public Service. Journal of Higher Education Outreach and Engagement 20:63-71

Hrotic S (2013) Survey of the philosophic discipline. Minerva, 51(1), 93-122.

Jaeger AJ, Thornton CH (2006) Neither Honor nor Compensation: Faculty and Public Service. Educational Policy 20:345-366. https://doi.org/10.1177/0895904805284050

Kitcher P (2011) Philosophy Inside Out. Metaphilosophy 42:248-260. https://doi.org/10.1111/j.1467-9973.2011.01684.x

Kitcher P (2001) Science, Truth, and Democracy. Oxford University Press, Oxford

Klavans R, Boyack KW (2017) Research portfolio analysis and topic prominence. Journal of Informetrics 11:1158-1174. https://doi.org/10.1016/j.joi.2017.10.002

Konkiel S (2016) Altmetrics: Diversifying the Understanding of Influential Scholarship. Social Science Research Network, Rochester, NY.

Langfeldt L, Scordato L (2016) Efficiency and flexibility in research funding. A comparative study of funding instruments and review criteria. Nordic Institute for Studies in Innovation, Research and Education

Macfarlane B (2007) Defining and Rewarding Academic Citizenship: The implications for university promotions policy. Journal of Higher Education Policy and Management 29:261-273. https://doi.org/10.1080/13600800701457863

McLevey J, Graham AV, Mcllroy-Young R, et al (2018) Interdisciplinarity and insularity in the diffusion of knowledge: an analysis of disciplinary boundaries between philosophy of science and the sciences. Scientometrics 117:331-349. https://doi.org/10.1007/s11192-018-2866-8

Mellers B, Hertwig R, Kahneman D (2001) Do Frequency Representations Eliminate Conjunction Effects? An Exercise in Adversarial Collaboration. Psychol Sci 12:269-275. https://doi.org/10.1111/1467-9280.00350

Moed HF (2017) Applied Evaluative Informetrics. Springer International Publishing

Moher D, Naudet F, Cristea IA, et al (2018) Assessing scientists for hiring, promotion, and tenure. PLOS Biology 16:e2004089. https://doi.org/10.1371/journal.pbio.2004089

Nguyen CT (2019) Manifesto for Public Philosophy. In: Daily Nous. https://dailynous.com/2019/07/01/manifesto-public-philosophy-guest-post-c-thi-nguyen/. Accessed 27 Jan 2021

Niles MT, Schimanski LA, McKiernan EC, Alperin JP (2020) Why we publish where we do: Faculty publishing values and their relationship to review, promotion and tenure expectations. PLOS ONE 15:e0228914. https://doi.org/10.1371/journal.pone.0228914

O'Meara K (2003) Reframing Incentives and Rewards for Community Service-Learning and Academic Outreach. $18: 201-220$ 
O'Meara KA (2005) Encouraging Multiple Forms of Scholarship in Faculty Reward Systems: Does It Make a Difference? Research in Higher Education 46:479-510

O'Meara K (2006) Encouraging Multiple Forms of Scholarship in Faculty Reward Systems: Influence on Faculty Work Life. Planning for Higher Education 34:43-53

O'Meara K (2008) Motivation for Faculty Community Engagement: Learning from Exemplars. JHEOE 12:7-30.

O'Meara K, Jaeger AJ (2006) Preparing Future Faculty for Community Engagement: Barriers, Facilitators, Models, and Recommendations. Journal of Higher Education Outreach and Engagement 11:3-26

Pedersen DB, Grønvad JF, Hvidtfeldt R (2020) Methods for mapping the impact of social sciences and humanities-A literature review. Res Eval 29:4-21. https://doi.org/10.1093/reseval/rvz033

Pence CH, Ramsey G (2018) How to Do Digital Philosophy of Science. Philosophy of Science 85:930941. https://doi.org/10.1086/699697

Peters I, Kraker P, Lex E, et al (2017) Zenodo in the Spotlight of Traditional and New Metrics. Front Res Metr Anal 2:13. https://doi.org/10.3389/frma.2017.00013

Philippi CL (2019) Well-Ordered Science's Basic Problem. Philosophy of Science 87:365-375. https://doi.org/10.1086/707539

Piwowar H (2013) Value all research products. Nature 493:159-159. https://doi.org/10.1038/493159a

Piwowar H, Priem J, Larivière V, et al (2018) The state of OA: a large-scale analysis of the prevalence and impact of Open Access articles. PeerJ 6:e4375. https://doi.org/10.7717/peerj.4375

Plaisance K, Graham AV, McLevey J, Michaud J (2019) Show me the numbers: a quantitative portrait of the attitudes, experiences, and values of philosophers of science regarding broadly engaged work. Synthese. 198(5):4603-4633. https://doi.org/10.1007/s11229-019-02359-7

Plaisance K, Elliott K (2020) A Framework for Analyzing Broadly Engaged Philosophy of Science. Philosophy of Science 88:594-615.

Plaisance KS, Michaud J, McLevey J. (2021). Pathways of influence: understanding the impact of philosophy of science in scientific domains. Synthese 199:4865-4896.

https://doi.org/10.1007/s11229-020-03007-1

Reale E, Avramov D, Canhial K, et al (2018) A review of literature on evaluating the scientific, social and political impact of social sciences and humanities research. Res Eval 27:298-308. https://doi.org/10.1093/reseval/rvx025

Rip A (2000) Higher forms of nonsense. European Review 8:467-485

Rose ME, Kitchin JR (2019) pybliometrics: Scriptable bibliometrics using a Python interface to Scopus. SoftwareX 10:100263. https://doi.org/10.1016/j.softx.2019.100263

Saltmarsh J, Giles Jr. DE, O'Meara K, et al (2009) Community engagement and institutional culture in higher education: An investigation of faculty reward policies at engaged campuses. In:

Creating our identities in service-learning and community engagement. IAP Information Age Publishing, Charlotte, NC, US, pp 3-29.

Sandmann L, Saltmarsh J, O'Meara K (2008) An Integrated Model for Advancing the Scholarship of Engagement: Creating Academic Homes for the Engaged Scholar. Journal of Higher Education Outreach and Engagement, 20(1):157-174

Sassower R (2018) The Refuge of the Academy: Response to Socrates Tenured. Philosophy of the Social Sciences 48:63-70. https://doi.org/10.1177/0048393117740828 
Schimanski LA, Alperin JP (2018) The evaluation of scholarship in academic promotion and tenure processes: Past, present, and future. F1000Res 7: https://doi.org/10.12688/f1000research.16493.1

Schwitzgebel, E. (2020, June 11). Diversity in Philosophy Departments: Introduction. Blog of the APA. Retrieved January 7, 2022, from https://blog.apaonline.org/2020/06/11/diversity-inphilosophy-departments-introduction/

Tiberius V (2017) The Well-Being of Philosophy. Proceedings and Addresses of the American Philosophical Association 91:65-86.

Tomašev N, Paquet U, Hassabis D, Kramnik V (2020) Assessing Game Balance with AlphaZero: Exploring Alternative Rule Sets in Chess. arXiv:200904374 [cs, stat]

Vaesen K, Katzav J (2019) The National Science Foundation and philosophy of science's withdrawal from social concerns. Studies in History and Philosophy of Science Part A 78:73-82. https://doi.org/10.1016/j.shpsa.2019.01.001

Vaesen K, Katzav J (2017) How much would each researcher receive if competitive government research funding were distributed equally among researchers? PLOS ONE 12:e0183967. https://doi.org/10.1371/journal.pone.0183967

van Dijk D, Manor O, Carey LB (2014) Publication metrics and success on the academic job market. Current Biology 24:R516-R517. https://doi.org/10.1016/i.cub.2014.04.039

Wang J (2013) Citation time window choice for research impact evaluation. Scientometrics 94:851872.

Ward K (1998) Addressing Academic Culture: Service Learning, Organizations, and Faculty Work. New Directions for Teaching and Learning 1998:73-80. https://doi.org/10.1002/tl.7309 White, S., Chu, R., \& Czujko, R. (2014). The 2012-13 survey of humanities departments at four-year institutions. (College Park, MD: Statistical Research Center, American Institute of Physics, 2014; sponsored by the American Academy of Arts \& Sciences).

White S., Chu R., \& Czujko R. The 2012-13 Survey of Humanities Departments at Four-Year Institutions (College Park, MD: Statistical Research Center, American Institute of Physics, 2014).

Wittkower DE, Selinger E, Rush L (2013) Public Philosophy of Technology: Motivations, Barriers, and Reforms. Techné: Research in Philosophy and Technology 17:179-200. https://doi.org/techne201317212

Zahedi Z, Costas R, Wouters P (2014) How well developed are altmetrics? A cross-disciplinary analysis of the presence of 'alternative metrics' in scientific publications. Scientometrics 101:1491-1513. https://doi.org/10.1007/s11192-014-1264-0 


\section{Supplementary materials}

A. Overview research expenses at institution [SUPRESSED]

\begin{tabular}{|l|l|l|l|}
\hline Type & Amount $(€)$ & Proportion & $\begin{array}{l}\text { Cost per full time } \\
\text { tenured philosopher } \\
\text { per year }(€)\end{array}$ \\
\hline $\begin{array}{l}\text { Research time (30\%) } \\
\text { of tenured staff }\end{array}$ & $5,955,236$ & $17.4 \%$ & 49,014 \\
\hline Project funding & $15,654,609$ & $45.8 \%$ & 128,844 \\
\hline $\begin{array}{l}\text { Personal funding PhD } \\
\text { \& PostDoc }\end{array}$ & $12,422,624$ & $26.3 \%$ & 102,243 \\
\hline $\begin{array}{l}\text { Institutional Bench } \\
\text { Fee }\end{array}$ & 144,000 & $0.4 \%$ & 1185 \\
\hline
\end{tabular}


B. Selection of journals and papers for test 1

1) Journals

- $\quad$ For CP, we selected the top 5 generalist journals as identified by Leiter's 2018 poll

(https://leiterreports.typepad.com/blog/2018/11/best-general-journals-of-philosophy-

2018.html): Mind, Nous, Philosophical Review, Journal of Philosophy, Philosophy and

Phenomenological Research

- For POVI, we selected the top 5 moral and political journals as identified by by Leiter's 2018 poll (https://leiterreports.typepad.com/blog/2018/11/the-best-journals-specializing-inmoral-andor-political-philosophy.html): Ethics, Philosophy and public affairs, The Journal of Political Philosophy, Journal of Moral Philosophy, Utilitas

- $\quad$ For POS, we selected, by impact factor, the best 5 journals that explicitly self-identify as limited to philosophy of science or HPS: BJPS, Philosophy of science, European Journal for Philosophy of Science, Biology \& Philosophy, Studies in history and philosophy of science

- Because 'Journal of philosophy', 'Philosophy \& Public affairs' and 'Journal of Political Philosophy' do not have abstracts, they were replaced by the next journals in the ranking indexed in WoS ('Australasian Journal of Philosophy', 'Politics, Philosophy and Economy' and 'Ethical Theory and Moral Practice').

2) Papers

- All data was downloaded from WOS on 19/10/2020.

- We included only thee document type 'articles'.

- We removed all papers without abstracts from the sample.

- For each kind of philosophy we selected the top $5 \%$ or $7.5 \%$ best cited articles (all databases) for each year between 2009 and 2019 (the percentage changing to ensure that we had a similarly sized sample for each kind of philosophy). 
C. Rating criteria for study 1

Below are the rating instructions that were given to all raters. The two main conditions discussed in the main paper were further clarified by means of four types of public relevance that are commonly used in the literature on research evaluation, namely, 'environmental relevance', 'socio-political relevance', 'economic relevance' and 'cultural relevance'. We emphasized, however, that papers do not need to fit in any of these categories to be relevant.

One might worry that the public relevance of philosophy abstracts doesn't always fit those generally accepted categories, and that because of that the judgement about their relevance is less reliable than when they do fit the categories. To control for this, we asked raters to indicate whether the abstracts that are relevant fit one of these categories. We then checked interrater reliability again omitting the papers that were rated as not fitting the classification. Since this didn't change the interrater reliability (Fleiss' Kappa 0.356), we concluded that the worry described above is not justified.

\section{Rating Instructions:}

- Read each of the abstracts in the Excel file carefully. After reading an abstract, rate it as 'publicly relevant' when at least one of the following two statements apply:

1) The authors aim to answer a question, resolve a problem or address an issue that is recognized as such by some people outside of academia.

2) If the claims of the authors would be accepted as true by people outside of academia, this would most likely have an effect on the behavior of these people.

- To rate an abstract 'publicly relevant', give it a 1 score. When the abstract is not 'publicly relevant' and so satisfies neither of the above two conditions, give it a 0 score.

- Please do not rate abstracts as 'publicly relevant' merely because the claims in the abstract add to the body of philosophical knowledge (i.e. knowledge for the sake of knowledge'). To be 'publicly relevant' the claims in the abstract should deal with an issue, problem or question that is recognized as such by people outside of academia (criterion 1) or possibly affect the behavior of people outside of academia (criterion 2).

- Please only take information provided in the abstract into consideration when rating the abstracts. This means you should not look for the full paper, or, if you happen to know or have read the paper, base your judgement on what you know about the full paper.

- When an abstract has been scored 1 on 'publicly relevant', we ask you to make one further distinction. Below is a list of four recognized types of public relevance. If the abstract you have rated as publicly relevant falls under one of these four types, give it a 1 score on 'fits classification'. If the abstract you have rated as publicly relevant does not fall under one of these four types, give it a 0 score on 'fits classification'.

A. Issues, problems or questions that have socio-political relevance: 
- Might this paper be useful to policy-makers?

- Does this paper provide new approaches to social issues?

- Does this paper inform ongoing public debate about societal issues?

- Might this paper improve the general quality of life of some?

○ $\quad \cdots . .$.

B. Issues, problems or questions that have environmental relevance:

- Does this paper add to the natural capital of a nation, for example by reduced waste and pollution, by increased uptake of recycling techniques, or by improved management of natural resources?

- Might this paper reduce environmental risk, or contribute to the preservation of biodiversity or adaptation to climate change?

○ $\quad \cdots$

C. Issues, problems or questions that have economical relevance:

- Does this paper enhance the skill base of a nation?

- Does this paper improve productivity?

- Might this paper lead to new products? Economic expansion? Wealth creation? Reduced costs? Increased innovation capability and global competitiveness? Improvements in science delivery?

D. Issues, problems or questions that have cultural relevance:

- Might this paper support greater understanding of where we have come from?

- Might this paper support greater understanding of who and what we are as a nation and society?

- Does this paper contribute to the preservation of the cultural heritage of a nation?

- Does this paper contribute to understanding of how we relate to other cultures and societies?

\section{Examples:}

Below we provide an example of an abstract that would not be rated publicly relevant (i.e., 0 on 'public relevance') and some examples of abstracts that would be rated publicly relevant (i.e., 1 on 'public relevance').

Of the abstracts that would be rated publicly relevant, some fall within one of the four types described above (i.e., 1 on 'fits classification') and others do not fall within one of the four types (i.e., 0 on 'fits classification').

\section{Not publicly relevant ( 0 on 'public relevance')}

Example: 
In recent years, Graham Priest and JC Beali have both defended two controversial theses: (1) the thesis that dialetheias (true contradictions) exist, and (2) the thesis that numbered among worldly items are negative facts which act as truthmakers for negative truths. In what follows, it is convenient to focus on the very clear defence of (2) offered by Beali [2000]. However, the same objections apply to Priest or anybody else who wishes to combine theses (1) and (2). I aim to show that the theory of negative facts favoured by Priest and Beali is incompatible with their dialetheism (though a replacement is urgently required by anyone who wants to maintain the sort of dialetheism defended by Priest and Beali alongside even a fairly weak truthmaker principle). (Stevens 2008, Logique et Analyse)

2. Publicly relevant ( 1 on 'public relevance') and falls within one of four types ( 1 on 'fits classification').

Example of socio-political relevance:

The problem raised when democratic majorities take decisions that impose restrictions on religious minorities may be avoided through 'the strategy of privatization', but not when the issue is the character of public space. This article considers a challenging case: the Swiss referendum decision to ban any future construction of Islamic minarets. It examines two grounds for opposition: the human right to freedom of religion, and the liberal principle of equal treatment of cultures. It argues that the human right is too limited, and that the equal treatment principle can be trumped by considerations of national identity when public space is involved. Nevertheless, the content of that identity and its public expression must remain open to democratic deliberation, and the Swiss decision can be faulted on those grounds. (Miller 2014 in BJPolS).

\section{Example of environmental relevance:}

Climate change represents an unprecedented threat to animal life on Earth, brought about by a single species: humanity. It is well-known that humans will suffer greatly as a result of continued climate change over the coming decades and centuries, but the calamitous effects on other animals are often downplayed. Here, the origins and potential scope of climate change are explored and the implications for the whole animal kingdom are summarized. It is argued that humans, as part of this kingdom, have both a responsibility and an imperative to take immediate steps to avert climate change for the sake of all animal life. (Thornes $2018 \mathrm{~J}$ of Animal Ethics)

\section{Example of economic relevance:}

Globalization is multifaceted and involves the interaction among businesses, services, governments, and societies beyond national borders. As a result, the flow of foreign direct investment (FDI), international trade in goods and services, and the economic interdependence of the nations of the world have been increasing. At the same time, much attention has been paid to the effect of corruption prevalent within many cultures and societies, and its impact on the economies, especially developing economies. This paper examines the relationship between human capital investment, the level of national corruption, and the global economic integration (GEI) of a nation in developing countries. 
Based on the data collected from over 60 countries, and building on the FDI and human capital theories, it was found that human capital investment and corruption are related to GEl. It was also found that the level of corruption moderates the relationship between human capital investment and GEI of developing economies. The findings of the study can help to deepen our understanding of $\mathrm{GEI}$ and have practical implications for developing countries in terms developing human capital, which plays a critical role in today's knowledge-based economy. (Bryant \& Javalgi 2016 J Bus Ethics)

\section{Example of cultural relevance:}

In the aftermath of the 'Brexit' referendum in the United Kingdom and the election of Donald J. Trump as president of the United States, Oxford Dictionaries chose the term 'post-truth' as Word of the Year 2016. 'Post-truth' was thereby defined as 'relating to or denoting circumstances in which objective facts are less influential in shaping public opinion than appeals to emotion and personal belief'. Ever since, the idea that the Western world has entered a 'post-truth era' has become widespread among journalists, political commentators, sociologists, and psychologists. It should not be surprising that philosophers have also weighed in on this topic. Truth is, after all, a philosophical theme par excellence, so the popular view that we nowadays live in a 'post-truth era' cannot but concern them. Furthermore, even many non-philosophers refer to a philosophical concept in order to interpret the 'post-truth phenomenon', namely the concept of 'bullshit' as Harry Frankfurt defined it in On Bullshit. None of these analyses, however, truly demonstrate why Frankfurt's notion of 'bullshit' can be considered a precursor of the term 'post-truth'. This essay tries to substantiate why Frankfurt indeed offers a most useful analysis of a 'post-truth attitude'. I will discuss four ways in which he distinguishes bullshit from lies - namely based on its intention, its scope, its method, and its harmfulness - and explain how each of these aspects of bullshit also characterize our 'post-truth era'. Each time, I will consider both those who spread bullshit and those who are exposed to it. In this way, I attempt to provide a conceptual framework for contemporary phenomena such as 'alternative facts,' internet trolls, fatigue of expertise, identity politics, the cult of authenticity, and disinformation. (Truwant 2020 in TvF)

\section{Publicly relevant ( 1 on 'public relevance') but does not fall within one of four types ( 0 on 'fits classification').}

\section{Example:}

Recent philosophical discussion concerning robots has been largely preoccupied with questions such as "can robots think, know, feel, or learn?" "can they be conscious, teleological, and self-adaptive?"; "can robots be in principle psychologically and intellectually isomorphic to men?"' Considerably less attention has been paid meanwhile to the question whether robots can be moral. Since the latter problem seems to me rather intimately connected with the ones extensively discussed, I would like to raise it here in an attempt to carry the discussion to its logical conclusion. The thesis of this paper is that if there are no magic descriptive terms-intelligence, consciousness, purposiveness, etc. -predicable exclusively of men but not of robots, then there are no such moral terms either. If men and machines coexist 
in a natural continuum in which there are no gaps, quantum jumps, or insurmountable barriers preventing the assimilation of the one to the other, then they also coexist in a moral continuum in which only relative but never absolute distinctions can be made between human and machine morality. I will argue this thesis by raising the question whether robots can be moral in two stages: (1) Can robots act morally? (2) Can we, without absurdity, treat robots as moral agents? The answer to these questions will be given, not in terms of a new "robot morality," but in terms of a few traditional ethical theories. (Verseny 1974 Ethics) 
D. Overview of research topics used in study 2

\begin{tabular}{|l|l|l|}
\hline Philosophy of Science & Philosophy of Value Issues & Core Philosophy \\
\hline Theory Change & Moral expressivism & Closure of knowledge \\
\hline The nature of models & The doctrine of dual effect & Minimalism and deflationism \\
\hline Species & Abortion & The exclusion problem \\
\hline Functions & Animal rights & Truthmakers \\
\hline $\begin{array}{l}\text { Mathematical structure of quantum } \\
\text { mechanics }\end{array}$ & Moral status of animals & Zombies \& conceivability problem \\
\hline Symmetry in physics & Rape and sexual violence & \\
\hline
\end{tabular}

For more on the selection and identification of these research topics, see Chi and Conix (2021) 
E. Description of the metrics measured in this study

\begin{tabular}{|c|c|c|c|}
\hline Category & Metric & Source & Description \\
\hline \multirow[t]{5}{*}{ Mentions } & Blog Mentions & $\begin{array}{l}\text { Blog lists curated by } \\
\text { PlumX }\end{array}$ & $\begin{array}{l}\text { The number of blog posts written about } \\
\text { the artifact }\end{array}$ \\
\hline & Comments & $\begin{array}{l}\text { Reddit, Slideshare, } \\
\text { Vimeo, YouTube }\end{array}$ & $\begin{array}{l}\text { The number of comments made about an } \\
\text { artifact }\end{array}$ \\
\hline & News Mentions & $\begin{array}{l}\text { News source lists } \\
\text { curated by PlumX }\end{array}$ & $\begin{array}{l}\text { The number of news articles written about } \\
\text { the artifact }\end{array}$ \\
\hline & $\begin{array}{l}\text { Q\&A Site } \\
\text { Mentions }\end{array}$ & Stack Exchange & $\begin{array}{l}\text { The number of mentions found about an } \\
\text { artifact }\end{array}$ \\
\hline & References & Wikipedia & $\begin{array}{l}\text { The number of references found to the } \\
\text { artifact }\end{array}$ \\
\hline \multirow[t]{2}{*}{$\begin{array}{l}\text { Social } \\
\text { Media }\end{array}$} & $\begin{array}{l}\text { Shares, Likes \& } \\
\text { Comments }\end{array}$ & Facebook & $\begin{array}{l}\text { The number of times a link was shared, } \\
\text { liked or commented on }\end{array}$ \\
\hline & Tweets & Twitter via Gnip & $\begin{array}{l}\text { The number of tweets and retweets that } \\
\text { mention the artifact }\end{array}$ \\
\hline \multirow[t]{5}{*}{ Citations } & Citation Indexes & Scopus & $\begin{array}{l}\text { The number of articles that cite the artifact } \\
\text { according to Scopus }\end{array}$ \\
\hline & Citation Indexes & CrossRef & $\begin{array}{l}\text { The number of articles that cite the artifact } \\
\text { according to CrossRef }\end{array}$ \\
\hline & Citation Indexes & SSRN & $\begin{array}{l}\text { The number of SSRN works that cite the } \\
\text { artifact }\end{array}$ \\
\hline & Citation Indexes & PubMed Central & $\begin{array}{l}\text { The number of PubMed Central articles } \\
\text { that cite the artifact }\end{array}$ \\
\hline & Clinical Citations & $\begin{array}{l}\text { PubMed Clinical } \\
\text { Guidelines }\end{array}$ & $\begin{array}{l}\text { The number of Clinical Guidelines from } \\
\text { PubMed that reference the artifact }\end{array}$ \\
\hline
\end{tabular}




\begin{tabular}{|l|l|l|l|}
\hline $\begin{array}{l}\text { Patent Family } \\
\text { Citations }\end{array}$ & $\begin{array}{l}\text { EPO, IPO, JPO, } \\
\text { USPTO, WIPO }\end{array}$ & $\begin{array}{l}\text { The number of patent families that } \\
\text { reference the artifact according to the } \\
\text { European Patent Office (EPO), World } \\
\text { Intellectual Property Organization (WIPO), } \\
\text { Intellectual Property Office of the United } \\
\text { Kingdom (IPO), United States Patent and } \\
\text { Trademark Office (USPTO) and Japan } \\
\text { Patent Office (JPO) }\end{array}$ \\
\hline
\end{tabular}

Source: Plum Analytics (https://plumanalytics.com/learn/about-metrics/) 
F. The average values of aggregated Mention and Social media metrics of 17 topics in the three kinds of philosophy (2000-2017)

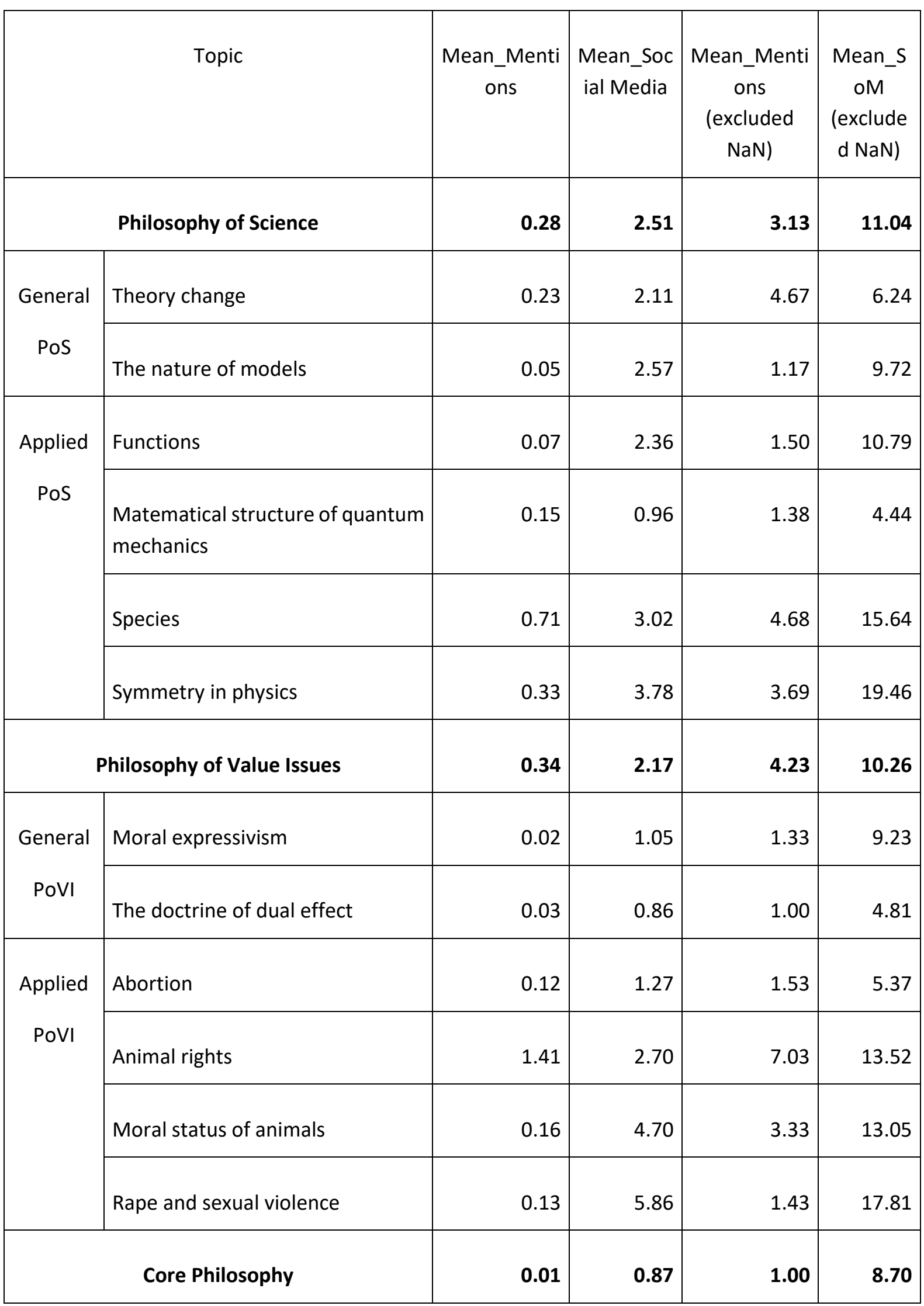




\begin{tabular}{|l|l|r|r|r|r|}
\hline Closure of knowledge & 0.00 & 0.85 & - & 9.00 \\
\hline $\begin{array}{l}\text { Minimalism and deflationism } \\
\text { about truth }\end{array}$ & 0.01 & 0.54 & 1.00 & 10.25 \\
\hline The exclusion problem & 0.01 & 0.73 & 1.00 & 10.67 \\
\hline $\begin{array}{l}\text { Truthmakers } \\
\text { Zombies and the conceivability } \\
\text { argument }\end{array}$ & 0.00 & 1.19 & 1.00 & 10.04 \\
\hline
\end{tabular}


G. List of journals for which reviewer instructions, aims and scope were surveyed

\begin{tabular}{|c|c|c|c|c|}
\hline Journal & $\begin{array}{l}\text { Uptake } \\
\text { isolation }\end{array}$ & $\begin{array}{l}\text { Content } \\
\text { isolation }\end{array}$ & Response & URL \\
\hline Philosophical Studies & 1 & 1 & yes & https://www.springer.com/journal/11098 \\
\hline Philosophical Review & 1 & 1 & yes & https://read.dukeupress.edu/the-philosophical-review/pages/About \\
\hline Journal of Philosophy & 1 & 1 & yes & http://www.journalofphilosophy.org/generalinfo.html \\
\hline Philosophy and Phenomenological Research & 1 & 1 & yes & https://onlinelibrary.wiley.com/page/journal/19331592/homepage/productinformation.html \\
\hline Philosophers imprint & 0 & 1 & yes & https://www.philosophersimprint.org/about.html \\
\hline Philosophy of science & 1 & 1 & no & https://journal.philsci.org/ \\
\hline Synthese & 1 & 1 & yes & https://www.springer.com/journal/11229 \\
\hline Canadian Journal of Philosophy & 1 & 1 & yes & http://www.canadianjournalofphilosophy.com/ \\
\hline Erkenntnis & 1 & 1 & yes & https://www.springer.com/journal/10670/aims-and-scope \\
\hline American Philosophical Quarterly & 1 & 1 & yes & https://www.press.uillinois.edu/journals/apq.html \\
\hline Pacific Philosophical Quarterly & 1 & 1 & no & https://onlinelibrary.wiley.com/page/journal/14680114/homepage/productinformation.html \\
\hline Ergo & 1 & 1 & yes & https://www.ergophiljournal.org/ \\
\hline European Journal of Philosophy & 1 & 1 & no & https://onlinelibrary.wiley.com/page/journal/14680378/homepage/productinformation.html \\
\hline Biology \& Philosophy & 1 & 0 & yes & https://www.springer.com/journal/10539 \\
\hline Journal of Philosophical logic & 1 & 1 & yes & https://www.springer.com/journal/10992 \\
\hline Philosophy and public affairs & 1 & 0 & yes & https://onlinelibrary.wiley.com/page/journal/10884963/homepage/productinformation.html \\
\hline The Journal of Political Philosophy & 1 & 1 & yes & https://onlinelibrary.wiley.com/page/journal/14679760/homepage/productinformation.html \\
\hline Utilitas & 1 & 1 & yes & https://www.cambridge.org/core/journals/utilitas \\
\hline The Journal of Ethics and Social Philosophy & 1 & 1 & yes & https://www.jesp.org/index.php/jesp \\
\hline Ethical Theory and Moral Practice & 1 & 0 & yes & https://www.springer.com/journal/10677 \\
\hline Mind & 1 & 1 & yes & https://academic.oup.com/mind \\
\hline Nous & 1 & 1 & yes & https://onlinelibrary.wiley.com/journal/14680068 \\
\hline Ethics & 1 & 1 & yes & https://www.journals.uchicago.edu/journals/et/about \\
\hline BJPS & 1 & 1 & no & https://academic.oup.com/bjps/pages/About \\
\hline Australasian Journal of Philosophy & 1 & 1 & yes & https://aap.org.au/AJP \\
\hline Philosophical Quarterly & 1 & 1 & no & https://academic.oup.com/pq/pages/About \\
\hline Analysis & 1 & 1 & yes & https://academic.oup.com/analysis/pages/About \\
\hline Studies in history and philosophy of science & 1 & 1 & no & https://www.journals.elsevier.com/studies-in-history-and-philosophy-of-science \\
\hline Journal of Moral Philosophy & 0 & 1 & no & https://brill.com/view/journals/imp/imp-overview.xml \\
\hline Oxford Studies in Metaethics & 1 & 1 & yes & $\begin{array}{l}\text { https://global.oup.com/academic/content/series/o/oxford-studies-in-metaethics- } \\
\text { osmet/?cc=be\&lang=en }\end{array}$ \\
\hline
\end{tabular}




\begin{tabular}{|c|c|c|c|c|}
\hline Oxford Studies in Normative Ethics & 1 & 1 & no & $\begin{array}{l}\text { https://global.oup.com/academic/content/series/o/oxford-studies-in-normative-ethics- } \\
\text { osne/?cc=be\&lang=en\& }\end{array}$ \\
\hline Oxford studies in Political Philosophy & 1 & 1 & no & $\begin{array}{l}\text { https://global.oup.com/academic/content/series/o/oxford-political-philosophy- } \\
\text { oxfpp/?cc=be\&lang=en\& }\end{array}$ \\
\hline The monist & 1 & 1 & no & https://academic.oup.com/monist \\
\hline The review of symbolic logic & 1 & 1 & no & $\begin{array}{l}\text { https://www.cambridge.org/core/journals/review-of-symbolic-logic/information/instructions- } \\
\text { contributors }\end{array}$ \\
\hline Studies part C & 1 & 1 & yes & $\begin{array}{l}\text { https://www.journals.elsevier.com/studies-in-history-and-philosophy-of-science-part-c-studies-in- } \\
\text { history-and-philosophy-of-biological-and-biomedical-sciences }\end{array}$ \\
\hline Journal of consciousness studies & 0 & 1 & yes & https://www.imprint.co.uk/product/jcs/ \\
\hline Journal of applied philosophy & 1 & 0 & yes & https://onlinelibrary.wiley.com/journal/14685930 \\
\hline Mind \& Language & 1 & 1 & yes & https://onlinelibrary.wiley.com/page/journal/14680017/homepage/productinformation.html \\
\hline Phenomenology and the cognitive sciences & 1 & 1 & yes & https://www.springer.com/journal/11097 \\
\hline Review of Philosophy and Psychology & 1 & 1 & yes & https://www.springer.com/journal/13164/aims-and-scope \\
\hline Linguistics and Philosophy & 1 & 1 & yes & https://www.springer.com/journal/10988/aims-and-scope \\
\hline Topoi & 1 & 1 & yes & https://www.springer.com/journal/11245 \\
\hline Philosophical Psychology & 1 & 1 & no & $\begin{array}{l}\text { https://www.tandfonline.com/action/journallnformation?show=editorialBoard\&journalCode=cph } \\
\underline{\text { p20 }}\end{array}$ \\
\hline HPLS & 1 & 1 & yes & https://www.springer.com/journal/40656/editors \\
\hline Ratio & 1 & 1 & no & https://onlinelibrary.wiley.com/page/journal/14679329/homepage/productinformation.html \\
\hline The review of metaphysics & 1 & 1 & yes & https://reviewofmetaphysics.org/ \\
\hline Thought & 1 & 1 & yes & https://onlinelibrary.wiley.com/page/journal/21612234/homepage/productinformation.html \\
\hline Economics \& Philosophy & 1 & 1 & yes & https://www.cambridge.org/core/journals/economics-and-philosophy/information \\
\hline Inquiry & 1 & 1 & yes & https://www.tandfonline.com/toc/sinq20/current \\
\hline Social Philosophy and Policy & 1 & 0 & no & $\begin{array}{l}\text { https://www.cambridge.org/core/journals/social-philosophy-and-policy/information/editorial- } \\
\text { board }\end{array}$ \\
\hline Oxford Studies in Ancient Philosophy & 1 & 1 & no & $\begin{array}{l}\text { https://global.oup.com/academic/content/series/o/oxford-studies-in-ancient-philosophy- } \\
\text { osap/?cc=be\&lang=en\& }\end{array}$ \\
\hline Metaphilosophy & 1 & 1 & no & https://onlinelibrary.wiley.com/journal/14679973 \\
\hline Journal of the history of philosophy & 1 & 1 & yes & https://www.press.jhu.edu/journals/journal-history-philosophy/editorial-board \\
\hline British journal for the history of philosophy & 1 & 1 & no & https://www.tandfonline.com/action/journallnformation?show=aimsScope\&journalCode=rbjh20 \\
\hline The journal of ethics & 1 & 1 & yes & https://www.springer.com/journal/10892/aims-and-scope \\
\hline European journal for philosophy of science & 0 & 0 & yes & https://www.springer.com/journal/13194 \\
\hline
\end{tabular}


H. List of important awards in philosophy with their value and description.

\begin{tabular}{|c|c|c|c|c|}
\hline Award name & Value (\$) & Relevant quote & $\begin{array}{l}\text { Explicit link } \\
\text { to public } \\
\text { relevance? }\end{array}$ & link \\
\hline $\begin{array}{l}\text { Berggruen Prize for } \\
\text { Philosophy and Culture }\end{array}$ & $1,000,000$ & $\begin{array}{l}\text { An annual } \$ 1 \text { million award } \\
\text { for major achievements in } \\
\text { advancing ideas that shape } \\
\text { the world. }\end{array}$ & yes & www.berggruen.org/prize/ \\
\hline $\begin{array}{l}\text { Kyoto Prize in Thought } \\
\text { and Ethics }\end{array}$ & 962,728 & $\begin{array}{l}\text { "A human being has no } \\
\text { higher calling than to strive } \\
\text { for the greater good of } \\
\text { humanity and the world." - } \\
\text { The Kyoto Prize honors } \\
\text { individuals based on this } \\
\text { philosophy. }\end{array}$ & yes & $\begin{array}{l}\text { www.kyotoprize.org/en/award } \\
\text {-field/thought-and-ethics-en/ }\end{array}$ \\
\hline $\begin{array}{l}\text { Fernando Gil } \\
\text { International Prize }\end{array}$ & 88,925 & $\begin{array}{l}\text { The Prize intends to award a } \\
\text { work of particular } \\
\text { excellence in the domain of } \\
\text { the Philosophy of Science, } \\
\text { whether regarding general } \\
\text { epistemological problems or } \\
\text { particular scientific areas. }\end{array}$ & no & $\begin{array}{l}\text { www.fernando- } \\
\text { gil.org.pt/en/award/ }\end{array}$ \\
\hline Meister Eckhart Prize & 50,000 & $\begin{array}{l}\text { It honors personalities who } \\
\text { address existential } \\
\text { questions of personal, social } \\
\text { and intercultural identity in } \\
\text { their work and who enliven } \\
\text { a broad public and } \\
\text { international discourse } \\
\text { through their work. }\end{array}$ & yes & $\begin{array}{l}\text { www.meister-eckhart- } \\
\text { preis.de/ }\end{array}$ \\
\hline Rolf Schock Prize & 46,392 & $\begin{array}{l}\text { A prize for work in logic and } \\
\text { philosophy. }\end{array}$ & no & $\begin{array}{l}\text { www.kva.se/en/priser/rolf- } \\
\text { schockprisen }\end{array}$ \\
\hline Rescher Prize & 30,000 & $\begin{array}{l}\text { Rewarding and showcasing } \\
\text { the work of philosophers } \\
\text { who have addressed the } \\
\text { historical "big questions" of } \\
\text { the field in ways that } \\
\text { nevertheless command the } \\
\text { respect of specialists. }\end{array}$ & no & $\begin{array}{l}\text { www.pitt.edu/ rescher/Resch } \\
\text { er\%20Prize.htm }\end{array}$ \\
\hline Karl Jaspers Prize & 29,641 & $\begin{array}{l}\text { a scientific work of } \\
\text { international standing that } \\
\text { is carried by a philosophical } \\
\text { spirit. }\end{array}$ & no & $\begin{array}{l}\text { www.heidelberg.de/hd,Lde/H } \\
\text { D/Rathaus/Karl Jaspers Preis. } \\
\text { html }\end{array}$ \\
\hline International Friedrich & 17,784 & [For] an essayistic, scientific & no & www.nietzsche- \\
\hline
\end{tabular}




\begin{tabular}{|c|c|c|c|c|}
\hline Nietzsche Prize & & $\begin{array}{l}\text { or literary single or } \\
\text { complete work on } \\
\text { philosophical subjects and } \\
\text { questions. }\end{array}$ & & $\begin{array}{l}\text { gesellschaft.de/nietzsche- } \\
\text { preis/preistr-ger/ }\end{array}$ \\
\hline Lakatos Award & 13,285 & $\begin{array}{l}\text { The award is given for a } \\
\text { monograph in the } \\
\text { philosophy of science } \\
\text { broadly construed, either } \\
\text { single authored or co- } \\
\text { authored, published in } \\
\text { English. }\end{array}$ & no & $\begin{array}{l}\text { www.Ise.ac.uk/philosophy/lak } \\
\text { atos-award/ }\end{array}$ \\
\hline
\end{tabular}

